\title{
Investimento público no Brasil e suas relações com ciclo econômico e regime fiscal *
}

\author{
Rodrigo Octávio Orair ${ }^{* *}, * * *$ \\ Fernando de Faria Siqueira ${ }^{* * * *}$
}

\begin{abstract}
Resumo
O artigo analisa a trajetória dos investimentos públicos na economia brasileira e suas relações com ciclo econômico e regime fiscal. A abordagem de Auerbach e Gorodnichenko (2012) é utilizada para estimar multiplicadores fiscais que variam conforme o ciclo econômico. Os multiplicadores do investimento público estimados para o Brasil podem alcançar valores elevados em recessões (superiores a 2) e muito mais baixos nas expansões (no máximo 0,8). Estes resultados dão subsídios ao uso do investimento público como instrumento de política anticíclica e também indicam que sua retração em conjunturas de crise econômica como em 2015 tem fortes repercussões negativas. Por fim, o artigo explora os fatores por trás da inflexão para uma trajetória de queda da taxa de investimentos a partir de 2011, com destaque para o papel do regime fiscal.
\end{abstract}

Palavras-chave: Investimento público; Multiplicador fiscal; Regime fiscal.

\section{Abstract \\ Public investment in Brazil and its relationships with business cycles and fiscal regime}

This article examines trends in Brazilian public investments and how they relate to business cycles and fiscal regime. The approach of Auerbach and Gorodnichenko (2012) is used to estimate fiscal multipliers that may change according to the business cycle. Public investment multipliers estimated for Brazil may reach high values during recessions (above 2) and much lower values in booms (at most 0.8). These results support the use of public investments as an instrument of anti-cyclical policy also in addition to the claim that cutting such investments during economic crisis as in the year 2015 has strong unfavorable repercussions. Finally, the article explores the main factors that lie behind the change towards a falling trend of public investments since 2011 with a particular emphasis on the role of the fiscal regime.

Palavras-chave: Public investment; Fiscal multiplier; Fiscal Regime.

JEL H60, H54.

\section{Introdução}

As escolas de pensamento econômico divergem nas suas análises sobre os impactos dos gastos públicos ou sobre a função do Estado como indutor do desenvolvimento econômico. Há, contudo, um reconhecimento bastante generalizado em relação ao papel estratégico que os investimentos do setor público podem desempenhar em nossas economias, principalmente

\footnotetext{
${ }^{*}$ Artigo recebido em 28 de setembro de 2016 e aprovado em 8 de janeiro de 2018.

** Técnico de Planejamento e Pesquisa do Instituto de Pesquisa Econômica Aplicada (Ipea), Brasília, DF, Brasil. E-mail: rodrigo.orair@ipea.gov.br.

${ }^{* * *}$ Pesquisador Associado ao International Policy Centre for Inclusive Growth (IPC-IG), Brasília, DF, Brasil.

${ }^{* * * *}$ Especialista em Regulação da Agência Nacional de Telecomunicações (Anatel), Brasília, DF, Brasil. E-mail: fariasiqueira.f@gmail.com.
} 
quando orientados para infraestrutura. Esses investimentos se distinguem da maior parte das demais despesas públicas porque resultam na acumulação de ativos fixos, que potencialmente ampliam o patrimônio líquido do setor público e geram um fluxo futuro de receitas, além de se tratar de uma variável macroeconômica que exerce efeitos simultâneos de estímulo sobre a demanda e sobre a oferta. Pelo lado da demanda, no curto prazo, as despesas de investimento estão associadas a multiplicadores do produto e do emprego mais elevados, sobretudo em períodos recessivos. Sob a ótica da oferta, possuem a faculdade de romper gargalos estruturais e ampliar a produtividade sistêmica da economia no médio e longo prazo.

Uma boa parte da teoria econômica argumenta ainda que a manutenção de um alto patamar de investimento público contribui para reduzir as flutuações da economia capitalista, dada a preferência dos empresários por ativos mais líquidos (como os títulos públicos) nos momentos de maior incerteza, ao contrário do governo, que não pauta suas decisões pelas perspectivas de lucro imediato. Sob tal perspectiva, a manutenção da taxa de investimento público em níveis estáveis e elevados pode reduzir a vulnerabilidade da economia às crises $\mathrm{e}$ atuar como um indutor do crescimento econômico.

É evidente que tais hipóteses são teóricas e há uma ampla literatura empírica que explora a relação entre investimentos públicos e crescimento econômico. Embora não seja unânime, a maior parte dos estudos, principalmente aqueles que incluem infraestrutura, encontram efeitos positivos significativos (Servén, 2007) ${ }^{1}$. No caso brasileiro, a literatura empírica é escassa devido à carência de informações, como iremos discutir com mais detalhes na seção 3 deste trabalho. Não obstante, existem estudos como os de Candido Júnior (2006) e Ferreira (1996) que, a partir de estimações com séries históricas anuais dos investimentos públicos, identificam uma relação de longo prazo positiva e estável entre produto e investimento público ou infraestrutura. Há ainda uma incipiente literatura destinada a estimar, a partir de dados trimestrais, o impacto dos diferentes gastos públicos sobre o crescimento (Pires, 2011; Pires, 2014; Castelo-Branco; Lima; Paula, 2015). Estes trabalhos recentes vêm encontrando multiplicadores fiscais dos investimentos públicos que são robustos $\mathrm{e}$ normalmente superiores à unidade, além de maiores do que os multiplicadores do consumo do governo que chegam a assumir valores negativos ou não significativos.

Apesar da reconhecida importância teórica e empírica, os investimentos nem sempre recebem a prioridade que deveriam e são candidatos preferenciais a sofrerem cortes orçamentários durante os processos de ajuste fiscal - seja por questões de economia política, rigidezes legais e institucionais, seja pelo foco excessivo no curto prazo, que faz com que retornos de longo prazo sejam negligenciados. Episódios de ajuste fiscal tendem a estar associados a cortes desproporcionais nos investimentos públicos, e isso cria um viés pró-cíclico

(1) Uma exceção é Warner (2014), que encontra uma relação fracamente positiva e restrita ao curto prazo, com poucas evidências de impactos positivos de longo prazo, ao analisar grandes projetos de infraestrutura em países de baixa renda. Sua crítica, contudo, está direcionada aos aspectos analíticos que distorcem as decisões (falhas na seleção e especificação de projetos, descontinuidades no financiamento, problemas de incentivos etc.) e não ao potencial dos investimentos de dinamizar a economia. 
Investimento público no Brasil e suas relações com ciclo econômico e regime fiscal

na política fiscal que amplifica as tendências depressivas da economia e impacta negativamente o crescimento econômico ${ }^{2}$.

Obviamente, a relação dos investimentos públicos com os ciclos econômicos, ou mesmo sua trajetória ao longo do tempo, não é tão simples e determinística. O volume de investimentos, assim como das demais despesas públicas, responde à orientação da política econômica e às prioridades de determinado governo, o que, por sua vez, estará condicionado pela maneira como funcionam suas instituições. Este arcabouço político-institucional se reflete no regime fiscal que diz respeito ao conjunto de regras e instituições que regem a condução da política fiscal.

Nas últimas décadas, disseminou-se ao redor do mundo a prática de regras fiscais que estabelecem limites numéricos sobre agregados orçamentários. A regra impõe uma restrição à política fiscal, sob os propósitos de assegurar disciplina fiscal e uma dinâmica sustentável do endividamento público. A primeira geração de regras fiscais, que prevaleceu na década de 1990 e início da de 2000, baseava-se em metas numéricas mais rígidas e com maior foco nos fluxos de caixa de curto prazo (por exemplo, metas anuais de resultado fiscal). Essas regras foram alvo de críticas por gerarem pouco espaço para ajuste a choques e riscos de distorcer a composição das despesas públicas e de minar a transparência devido aos incentivos à contabilidade criativa.

Diante do reconhecimento de que metas com essas características induzem vieses antiinvestimento e pró-cíclico na política fiscal, surgiram duas ondas revisionistas com propostas de aprimoramentos nos regimes fiscais. A primeira, em meados dos anos 2000, por uma série de trabalhos sugerindo regras que combinem incentivos aos investimentos públicos com sustentabilidade fiscal no médio prazo ${ }^{3}$. Uma segunda onda revisionista surgiu como resposta ao legado fiscal da crise internacional de 2008, com sugestões de regras que acomodassem mais explicitamente os efeitos dos ciclos econômicos e conferissem maior flexibilidade para lidar com períodos de desaceleração econômica.

Vários países promoveram reformas institucionais nos últimos anos para introduzir uma "nova geração de regras fiscais" mais flexível e com âncora fiscal de médio prazo, sob a visão de que se deve buscar a sustentabilidade da dívida pública, mas sem atuar contrariamente ao crescimento econômico4. Entre os países membros da União Europeia, por exemplo,

(2) Relação amplamente documentada na literatura macroeconômica tanto nos países desenvolvidos quanto nos países em desenvolvimento. Por exemplo, Calderón, Easterly e Servén (2003) mostram que quase metade do ajuste fiscal dos países latino-americanos na década de 1990 foi obtido por cortes nos investimentos em infraestrutura. Schettini et al. (2011) apresentam evidências da pró-ciclicidade da política físcal no Brasil.

(3) Mais comumente, as propostas passam pela separação do orçamento de despesas de capital, passível de ser financiado por endividamento, das demais despesas que permanecem submetidas a regras mais rígidas. Seja na sua versão mais ampla, como Blanchard e Giavazzi (2004), que sugerem retomar a regra do ouro, segundo a qual todos os investimentos estão liberados para serem financiados por dívida, seja na versão mais restrita, de Mintz e Smart (2006) e Servén (2007), que incluem apenas projetos de investimentos autofinanciáveis.

(4) Para a discussão da nova geração de regras fiscais, ver Schaechter, Kinda, Budina e Weber (2012) e Gobetti (2014). 
ampliou-se o uso de metas fiscais estruturais ajustadas ao ciclo econômico com cláusulas de escape, que permitem que as restrições fiscais sejam temporariamente relaxadas em situações extraordinárias como as crises econômicas. Complementarmente, desde 2011 vários destes países estão adotando uma restrição adicional de limitar o crescimento da despesa à taxa de crescimento de longo prazo do PIB.

No Brasil, a discussão sobre regras fiscais foi protelada por vários anos e apenas recentemente foi reaberta, sob condições desfavoráveis, em meio a uma profunda crise política, fiscal e econômica que, simultaneamente, exige ação imediata e restringe o raio de ação do governo. Fatores como a conjuntura adversa das finanças públicas, juntamente com a avaliação de que as práticas fiscais dos últimos anos minaram a transparência e a credibilidade do atual regime fiscal brasileiro, influenciaram decisivamente para que o governo propusesse um novo regime fiscal que restringe o crescimento das despesas primárias do governo central à reposição da inflação (Proposta de Emenda à Constituição n. 159 de 2015). Tal regra denominada de nominalismo é bastante rigorosa - por exemplo, porque estabelece crescimento real nulo das despesas enquanto as experiências semelhantes nos países europeus permitem que as despesas cresçam no mesmo ritmo das estimativas do PIB no longo prazo -, e vem levantando uma série de preocupações e questionamentos sobre sua viabilidade. Uma dessas preocupações é a possibilidade de penalização excessiva dos investimentos públicos.

O propósito do artigo é contribuir com esse debate buscando um melhor entendimento sobre os fatores que estão por trás da trajetória dos investimentos públicos na economia brasileira e suas relações com o ciclo econômico e o regime fiscal. O texto está organizado em seis seções, incluindo esta introdução. A próxima seção analisa a trajetória da taxa de investimentos públicos na economia brasileira, com ênfase no período recente caracterizado por um esboço de retomada (2006-2010) e inflexão para uma tendência de queda (2011-2015) que fez com que o avanço anterior tenha sido quase todo revertido.

As duas seções seguintes são dedicadas aos questionamentos: Qual o impacto da trajetória da taxa de investimentos públicos sobre o ritmo de atividade econômica? Quais fatores estariam por trás da queda recente da taxa de investimentos? Para explorar a relação entre investimentos públicos e crescimento econômico, a terceira seção faz uso de um modelo econométrico não linear que estima multiplicadores fiscais variáveis conforme o estado do ciclo econômico. Será adotada a mesma modelagem de Auerbach e Gorodnichenhko (2012), com algumas adaptações para os dados brasileiros, que possui a grande vantagem de permitir que se avalie se a resposta do produto em relação ao investimento público é maior (ou menor) em períodos recessivos (ou expansivos).

A quarta seção apresenta um conjunto de hipóteses explicativas para a queda recente da taxa de investimentos públicos. A hipótese central deste artigo diz respeito aos constrangimentos orçamentários aos investimentos que foram flexibilizados no período 20062010 e retornaram de maneira mais aguda no período a partir de 2011. À primeira vista, tal hipótese pode soar paradoxal porque a interrupção da retomada dos investimentos públicos e o 
Investimento público no Brasil e suas relações com ciclo econômico e regime fiscal

início do seu retrocesso ocorreu durante um período de expansionismo fiscal (2011-2014). Por isso, a quinta seção do texto avança na avaliação desta hipótese, a partir de uma análise mais geral da política fiscal no Brasil que explora as relações dos investimentos públicos com o regime fiscal. Seguem-se as considerações finais em que se procura destacar a atual situação de fragilidade dos investimentos públicos no arcabouço fiscal brasileiro. Essa reflexão é crucial no momento em que o país rediscute seu regime fiscal, porque traz à tona a necessidade de que a avaliação de alternativas de estratégias fiscais leve em consideração as repercussões dos investimentos públicos sobre o crescimento econômico e sobre a sustentabilidade das finanças públicas.

\section{Trajetória da taxa de investimentos públicos na economia brasileira}

Analisar a trajetória dos investimentos públicos na economia brasileira requer alguns cuidados especiais. Em primeiro lugar, porque o conceito investimento é muitas vezes utilizado de forma pouco precisa. Ao longo do texto, o termo será sinônimo de formação bruta de capital fixo (FBCF), que é um conceito mais restrito ${ }^{5}$. Uma segunda dificuldade diz respeito à presença de componentes cíclicos que podem induzir analistas a interpretar erroneamente as oscilações conjunturais como mudanças na tendência. É possível identificar ao menos três ciclos muito característicos nos investimentos públicos brasileiros que se diferenciam em termos de periodicidade.

Um primeiro é um ciclo de prazo mais longo com ascensão no período pós-Guerra, auge no final da década de 1970 e declínio nas décadas seguintes, até atingir o patamar histórico mais baixo no início do século XXI (Gráfico 1). Este movimento de ascensão e queda do investimento público está relacionado com o modelo de desenvolvimento da economia brasileira e seu padrão de intervenção estatal subjacente. A ascensão do modelo de desenvolvimento sob o Estado intervencionista (1930-1979) ocasionou a expansão da taxa de investimento público que tinha a função de promover a transformação estrutural e o crescimento econômico, mediante ampliação do escopo de ação do setor produtivo estatal.

No declínio deste modelo, durante as décadas de 1980 e 1990, foram colocados inúmeros constrangimentos orçamentários ao investimento público, diante de um quadro de crise fiscal e desarticulação do padrão de financiamento estatal. Paralelamente a isso, houve a implementação de uma estratégia de desestatização da economia, via desmonte do aparato do Estado desenvolvimentista, que dera suporte à expansão dos investimentos públicos no período anterior, e transferência da responsabilidade de parte considerável dos investimentos para a iniciativa privada.

(5) Os dados de investimento público utilizados neste artigo são de Orair (2016) cujo apêndice apresenta as definições conceituais e descreve as fontes primárias de dados. É comum que estudos e relatórios fiscais utilizem conceitos amplos que incluem despesas que não compõe a FBCF, como, por exemplo, capitalizações de empresas estatais, aquisições de imóveis não relacionados a uma obra, transferências de capital aos entes subnacionais e até mesmo subsídios aos investimentos privados. 
Não se deseja retomar de maneira aprofundada a análise histórica já realizada em Pêgo Filho, Cândido Júnior e Pereira (1999), Afonso e Biasoto Júnior. (2007) e Orair e Gobetti (2010), entre tantos outros. Para os propósitos deste artigo, o mais importante é destacar os indícios de um novo ciclo de menor duração da taxa de investimentos públicos, interpondo-se ao ciclo histórico mais longo, com uma fase de ascensão no quinquênio 2006-2010 e inflexão para uma fase descendente no quinquênio 2011-2015. Essa trajetória reflete um ciclo de médio prazo da política fiscal que transitou de uma fase contracionista (1999-2005) para uma fase expansionista (2006-2014). Sendo que nesta última o espaço fiscal foi canalizado predominantemente para expansão dos investimentos em um primeiro subperíodo (2006-2010) e no subperíodo subsequente reorientado para maior expansão das despesas de custeio e subsídios e das desonerações tributárias (2011-2014), como analisaremos com mais detalhes na seção $5^{6}$.

Gráfico 1

Investimentos públicos (1947-2015) ${ }^{1}$

(Em participação percentual do PIB)

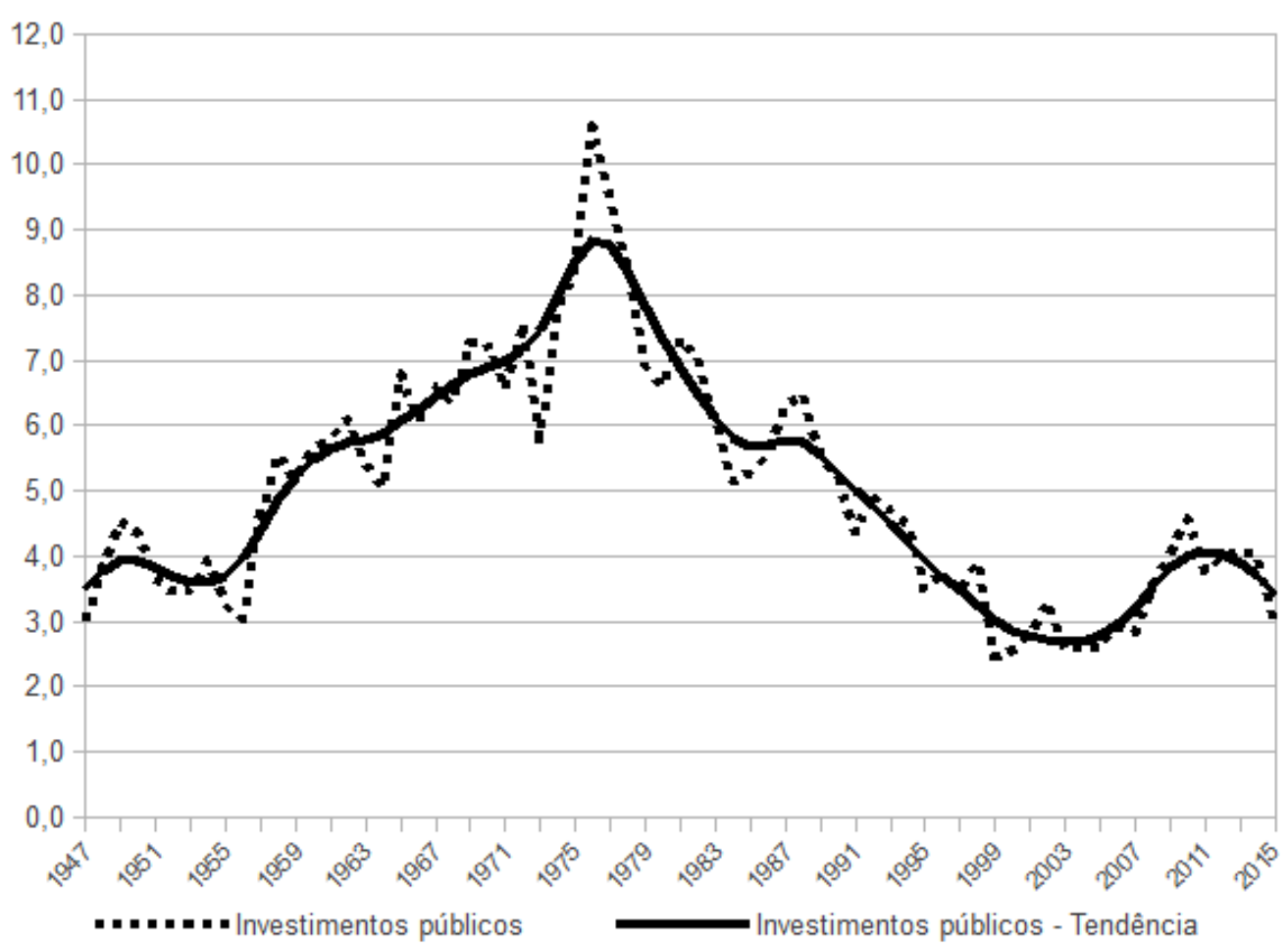

Notas: ${ }^{1}$ Considera-se o total do governo geral e das empresas estatais federais.

${ }^{2}$ A tendência foi extraída pelo filtro Hodrick-Prescott.

Elaboração dos autores, a partir de dados do produto interno bruto (PIB) do Sistema de Contas Nacionais (SCN) do Instituto Brasileiro de Geografia e Estatística (IBGE) e investimentos públicos de Orair (2016).

(6) Segue-se aqui a periodização da política fiscal de Gobetti e Orair (2015). 
Investimento público no Brasil e suas relações com ciclo econômico e regime fiscal

A visualização da trajetória da taxa de investimentos públicos no período mais recente pode ser feita com maior clareza no Gráfico 2. O mesmo gráfico revela uma terceira natureza de ciclo, vinculada ao calendário político, de prazo mais curto (quatro anos) e com formato de vale: são duas fases de aceleração nos períodos pré-eleitorais, sendo a primeira mais intensa, nas eleições presidenciais e de governadores (1998, 2002, 2006, 2010 e 2014), e a segunda menos forte, nas eleições de prefeitos (1996, 2000, 2004, 2008 e 2012). Por isto, o mais apropriado é que as comparações considerem anos equivalentes do calendário eleitoral ou façam uso de procedimentos para controlar a presença dos ciclos políticos eleitorais ${ }^{7}$.

Gráfico 2

Investimentos públicos (1995-2015)

(Valores mensais anualizados em participação percentual do PIB)

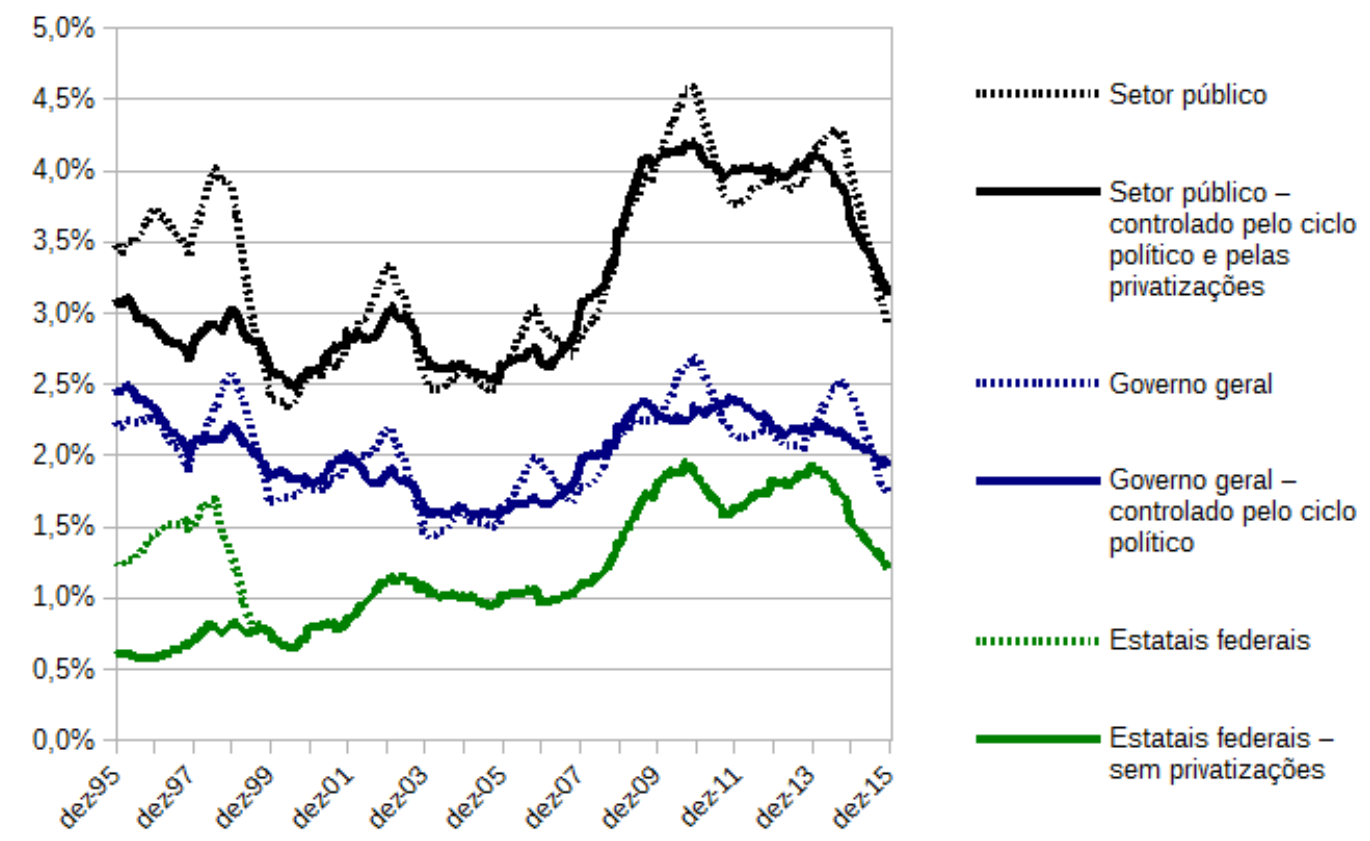

Elaboração dos autores, a partir dos dados do indicador mensal do PIB do Banco Central (Bacen) e investimentos públicos de Orair (2016).

Obs.: ${ }^{1} \mathrm{O}$ componente do ciclo político eleitoral foi extraído por um modelo estrutural básico de séries temporais.

${ }^{2}$ A série sem privatizações deduz os investimentos de empresas que deixaram de fazer parte do setor público, a exemplo da Companhia Vale do Rio Doce e da Telebras.

${ }^{3} \mathrm{O}$ total de investimentos do setor público é uma aproximação com a soma do governo geral e das estatais federais.

(7) Orair, Gouvêa e Leal (2014) apresentam evidências empíricas dos ciclos políticos eleitorais nos investimentos públicos e uma resenha com suas explicações teóricas, que vão desde a necessidade de promover um ajuste fiscal em resposta à maior pressão do mercado às políticas de pleno emprego, pressão esta que ameniza durante o período eleitoral, até a possibilidade de influenciar os resultados das eleições com obras de maior visibilidade e que sinalizam competência administrativa. 
Feita essa ressalva, vê-se que a taxa de investimentos públicos alcançou o auge do período recente de 4,6\% do PIB no ano eleitoral de 2010, que representa acréscimo de $1,7 \%$ ponto percentual (p.p.) em relação aos 2,9\% do PIB verificados em 2006. A comparação não se modifica quando considerada a série que controla o efeito do ciclo eleitoral: seu auge foi de $4,2 \%$ do PIB em 2010 e o acréscimo de 1,6 p.p. sobre os $2,6 \%$ do PIB de 2006 . No período após 2010, a taxa de investimentos públicos passou a mostrar tendência de declínio (ou ao menos estagnação), com pronunciada queda a partir do último trimestre de 2014. A estimativa da taxa de investimentos públicos em 2015 é de 2,9\% do PIB (ou 3,1\% do PIB na série que controla o efeito do ciclo eleitoral), que é um patamar muito próximo daquele observado em 2007 e também em 1995. Ou seja, a retração do quinquênio 2011-2015 reverteu quase todo o avanço anterior e ainda fez com que a taxa de investimentos públicos retomasse patamares semelhantes aos de meados da década de 1990.

A desaceleração recente dos investimentos públicos fica ainda mais evidente ao compararmos as taxas reais de crescimento (Tabela 1). Há um enorme contraste entre o crescimento superior a dois dígitos durante 2007-2010 - período de maior dinamismo econômico das duas últimas décadas, mesmo tendo atravessado o pior momento da crise internacional de 2008 -, em relação a 2011-2014, quando os investimentos permaneceram quase estagnados e a economia adentrou um período de desaceleração econômica.

A ascensão dos investimentos no quinquênio 2006-2010 reflete não somente a flexibilização da política fiscal, que removeu temporariamente entraves orçamentários, mas também uma mudança de posicionamento do governo, no sentido de reassumir seu papel no planejamento estratégico. Essa mudança foi consubstanciada na formulação de programas estratégicos e na retomada de grandes projetos de investimentos.

À época, consolidou-se o diagnóstico de que o resultado das reformas liberalizantes da década de 1990 foram desiguais. A expansão dos investimentos privados em infraestrutura ficou muito restrita aos segmentos mais atraentes e, na maioria dos demais segmentos, o avanço privado não se refletiu no aumento dos investimentos em magnitude suficiente para compensar a queda nos gastos públicos. Explicitando-se uma incapacidade de se alocar recursos na manutenção e expansão da infraestrutura do país, recolocando gargalos ao crescimento, prejudicando a competitividade sistêmica e contribuindo para o fraco crescimento econômico do período. Mais do que mera transferência de responsabilidades à iniciativa privada, houve reconcentração setorial e reconfiguração das articulações entre investimento público e privado, cabendo ao Estado, em conformidade com esse diagnóstico, assumir uma posição mais pragmática para promover a retomada dos investimentos, via intervenção direta ou indireta, por meio de arranjos remodelados com o setor privado, nos quais as empresas, bancos e fundos públicos desempenhariam papel proeminente ${ }^{8}$.

(8) Bielschowsky (2002) faz um balanço das reformas e da infraestrutura no Brasil, e Pêgo Filho e Campos Neto (2010) mapeiam seus gargalos. Orair (2014) analisa a relação entre a retomada dos investimentos públicos e as grandes obras de infraestrutura, assim como os novos arranjos patrimoniais. 
Tabela 1

Investimentos públicos (1994/2015)

(Em bilhões de R $\$$ de 2015 convertidos pelo deflator implícito do PIB)

\begin{tabular}{|c|c|c|c|c|c|c|c|}
\hline Ano & $\begin{array}{c}\text { Governo } \\
\text { central } \\
\end{array}$ & $\begin{array}{l}\text { Governo } \\
\text { estadual }\end{array}$ & $\begin{array}{c}\text { Governo } \\
\text { municipal }\end{array}$ & $\begin{array}{c}\text { Governo } \\
\text { geral }\end{array}$ & $\begin{array}{l}\text { Estatais } \\
\text { federais }\end{array}$ & $\begin{array}{c}\text { Setor } \\
\text { público }\end{array}$ & PIB \\
\hline \multicolumn{8}{|c|}{ Valores em bilhões de $\mathrm{R} \$$} \\
\hline 1994 & 23,8 & 46,0 & 38,0 & 107,8 & 43,3 & 151,1 & $3.371,5$ \\
\hline 1995 & 20,0 & 18,5 & 40,3 & 78,8 & 43,9 & 122,7 & $3.522,2$ \\
\hline 1996 & 17,9 & 24,1 & 40,6 & 82,7 & 52,0 & 134,6 & $3.600,0$ \\
\hline 1997 & 19,7 & 30,6 & 25,3 & 75,6 & 55,4 & 131,0 & $3.722,2$ \\
\hline 1998 & 19,3 & 47,4 & 30,0 & 96,8 & 48,9 & 145,6 & $3.734,8$ \\
\hline 1999 & 12,7 & 20,7 & 29,0 & 62,4 & 28,9 & 91,3 & $3.752,3$ \\
\hline 2000 & 12,2 & 27,4 & 30,0 & 69,6 & 30,3 & 99,9 & $3.916,9$ \\
\hline 2001 & 17,4 & 34,2 & 26,0 & 77,6 & 33,8 & 111,5 & $3.971,4$ \\
\hline 2002 & 18,4 & 32,0 & 39,0 & 89,4 & 45,6 & 135,0 & $4.092,6$ \\
\hline 2003 & 8,1 & 21,9 & 30,9 & 60,9 & 45,0 & 105,8 & $4.139,3$ \\
\hline 2004 & 9,4 & 25,6 & 34,7 & 69,7 & 44,0 & 113,7 & $4.377,7$ \\
\hline 2005 & 15,0 & 29,5 & 27,6 & 72,0 & 45,4 & 117,4 & $4.517,9$ \\
\hline 2006 & 18,0 & 34,5 & 39,2 & 91,7 & 45,6 & 137,3 & $4.696,9$ \\
\hline 2007 & 21,0 & 24,7 & 41,1 & 86,7 & 53,7 & 140,4 & $4.982,0$ \\
\hline 2008 & 23,0 & 36,3 & 53,1 & 112,4 & 72,0 & 184,5 & $5.235,8$ \\
\hline 2009 & 31,2 & 46,9 & 39,4 & 117,5 & 93,3 & 210,7 & $5.229,2$ \\
\hline 2010 & 44,4 & 58,0 & 49,8 & 152,2 & 105,1 & 257,3 & $5.622,9$ \\
\hline 2011 & 35,1 & 40,2 & 49,5 & 124,8 & 94,9 & 219,7 & $5.842,7$ \\
\hline 2012 & 32,3 & 40,6 & 55,9 & 128,8 & 107,9 & 236,7 & $5.954,8$ \\
\hline 2013 & 38,9 & 53,9 & 38,7 & 131,5 & 117,9 & 249,4 & $6.134,2$ \\
\hline 2014 & 43,8 & 62,4 & 45,3 & 151,5 & 95,2 & 246,7 & $6.140,6$ \\
\hline 2015 & 27,2 & 34,3 & 44,7 & 106,2 & 71,2 & 177,4 & $5.904,3$ \\
\hline \multicolumn{8}{|c|}{ Taxa de crescimento ao ano } \\
\hline $1995-1998$ & $-5,1 \%$ & $0,8 \%$ & $-5,7 \%$ & $-2,7 \%$ & $3,1 \%$ & $-0,9 \%$ & $2,6 \%$ \\
\hline 1999-2002 & $-1,2 \%$ & $-9,4 \%$ & $6,8 \%$ & $-2,0 \%$ & $-1,7 \%$ & $-1,9 \%$ & $2,3 \%$ \\
\hline 2003-2006 & $-0,6 \%$ & $1,9 \%$ & $0,1 \%$ & $0,6 \%$ & $0,0 \%$ & $0,4 \%$ & $3,5 \%$ \\
\hline $2007-2010$ & $25,4 \%$ & $13,8 \%$ & $6,1 \%$ & $13,5 \%$ & $23,2 \%$ & $17,0 \%$ & $4,6 \%$ \\
\hline 2011-2014 & $-0,4 \%$ & $1,9 \%$ & $-2,4 \%$ & $-0,1 \%$ & $-2,4 \%$ & $-1,0 \%$ & $2,2 \%$ \\
\hline 2012-2015 & $-6,2 \%$ & $-3,9 \%$ & $-2,5 \%$ & $-4,0 \%$ & $-6,9 \%$ & $-5,2 \%$ & $0,3 \%$ \\
\hline
\end{tabular}

Elaboração dos autores, a partir das fontes de dados do PIB do SCN/IBGE e investimentos públicos de Orair (2016).

O fato é que a taxa de investimentos públicos, em um primeiro momento, nos anos 2006-2010, respondeu favoravelmente ao reposicionamento estratégico do governo e à 
flexibilização da política fiscal. Logo em seguida, o esboço de retomada foi interrompido e a taxa de investimentos públicos passou a declinar mesmo no período 2011-2014 caracterizado pelo expansionismo fiscal. Estas constatações suscitam alguns questionamentos: Qual é o impacto da queda na taxa de investimentos sobre o ritmo de atividade econômica? Quais fatores estariam por trás desta queda? As próximas seções são dedicadas a esses questionamentos.

\section{Multiplicadores dos investimentos públicos: uma estimação por Stvar}

\subsection{Estimação de multiplicadores fiscais: aspectos metodológicos}

A crise internacional de 2008 reergueu o debate acerca da importância da política fiscal anticíclica e, mais notadamente, da proposição de inspiração keynesiana de que os multiplicadores fiscais tendem a ser maiores durante as crises econômicas. Sob esse pano de fundo, vem proliferando um ramo de pesquisa empírica dedicado a estimar multiplicadores fiscais que variam conforme o estado do ciclo econômico?

Por exemplo, Auerbach e Gorodnichenko (2012) empregam um modelo vetorial autorregressivo com mudança de regime em que as transições entre os estados são suaves (smooth transition vector autoregression - STVAR), de modo a permitir respostas diferenciadas entre recessões e expansões. A especificação econométrica adotada pelos autores segue o sistema de equações:

$$
\begin{aligned}
& \boldsymbol{X}_{t}=\left(1-F\left(z_{t-1}\right)\right) \boldsymbol{\Pi}_{\boldsymbol{E}}(L) \boldsymbol{X}_{\boldsymbol{t}-\mathbf{1}}+F\left(z_{t-1}\right) \boldsymbol{\Pi}_{\boldsymbol{R}}(L) \boldsymbol{X}_{\boldsymbol{t}-\mathbf{1}}+\boldsymbol{u}_{\boldsymbol{t}} \\
& \boldsymbol{u}_{\boldsymbol{t}} \sim N\left(\mathbf{0}, \boldsymbol{\Omega}_{\boldsymbol{t}}\right) \\
& \boldsymbol{\Omega}_{\boldsymbol{t}}=\boldsymbol{\Omega}_{\boldsymbol{E}}\left(1-F\left(z_{t-1}\right)\right)+\boldsymbol{\Omega}_{\boldsymbol{R}} F\left(z_{t-1}\right) \\
& F\left(z_{t}\right)=\frac{\exp \left(-\gamma z_{t}\right)}{1+\exp \left(-\gamma z_{t}\right)} \\
& \operatorname{var}\left(z_{t}\right)=1, E\left(z_{t}\right)=0
\end{aligned}
$$

no qual $\boldsymbol{X}_{\boldsymbol{t}}=\left[\boldsymbol{G}_{\boldsymbol{t}} \boldsymbol{T}_{\boldsymbol{t}} \boldsymbol{Y}_{\boldsymbol{t}}\right]^{\prime}$ é um vetor de variáveis com as séries dos gastos públicos, receitas públicas e $\mathrm{PIB}^{10}$. A variável $z_{t}$ na equação (4) é um índice que captura a transição entre as fases do ciclo econômico, assumindo valores positivos nos períodos de expansão e negativos nas recessões. Essa variável é normalizada para ter variância unitária de modo que $\gamma$ seja invariante com a escala e, por construção, adota-se $\gamma>0$. Assim, a equação (4) define que os

(9) Tais estudos podem ser classificados de acordo com a técnica econométrica utilizada: i) modelos de vetor auto regressivo (VAR) de parâmetros variáveis no tempo com volatilidade estocástica (Kirchner, Cimadomo e Hauptmeier, 2010); ii) VAR com limiar (threshold) [Baum; Poplawski-Ribeiro; Ribeiro, 2012]; iii) Regressões em painéis e técnicas Var (Corsetti; Meier; Miler 2012; Ilzetzki; Mendoza; Vgh, 2013; Auerbach; Gorodnichenko, 2011); iv) Var com mudança de regime (Auerbach; Gorodnichenko, 2012; Cos; .oral-Benito, 2013).

(10) Este ordenamento das variáveis em $\boldsymbol{X}_{\boldsymbol{t}}$ implica que choques nas receitas e no produto não possuem efeitos contemporâneos sobre o gasto e que choques das receitas afetam o produto contemporaneamente, não valendo o argumento recíproco. Como usual na literatura, os argumentos básicos para identificação são os de que a arrecadação responde com certa defasagem ao PIB e que o processo orçamentário é mais lento porque leva mais de um período para que as autoridades políticas e fiscais internalizem determinado choque do produto e respondam via política fiscal. 
Investimento público no Brasil e suas relações com ciclo econômico e regime fiscal

períodos de recessão (suficientemente) forte são aqueles em que $F(z)$ está próximo da unidade $(F(z) \approx 1)$ com o comportamento do sistema sendo descrito por $\boldsymbol{\Pi}_{\boldsymbol{R}}$ e $\boldsymbol{\Omega}_{\boldsymbol{R}}$. O raciocínio análogo vale para uma expansão (suficientemente) forte $(1-F(z) \approx 1)$ quando $\boldsymbol{\Pi}_{\boldsymbol{E}}$ e $\boldsymbol{\Omega}_{\boldsymbol{E}}$ descrevem o comportamento do sistema. No limite, pode-se interpretar $F(z)$ de maneira simplificada como a probabilidade de se estar em uma recessão.

Os resultados de Auerbach e Gorodnichenko (2012) para a economia norte-americana do pós-guerra indicam que os multiplicadores diferem consideravelmente de acordo com o estado do ciclo econômico e com o componente de gasto. As estimativas de multiplicadores dos gastos públicos nas recessões (entre 1 e 1,5) mostram-se consideravelmente mais elevadas do que nas expansões (de 0 a 0,5 ), ao passo que os resultados do modelo linear ficaram próximos da unidade. Quando é introduzida a decomposição dos gastos públicos, encontramse resultados de multiplicadores dos investimentos mais robustos (chegam a exceder 2) do que os do consumo do governo (em torno de 0,5 ) e em ambos os casos são maiores na recessão do que na expansão.

A evidência empírica sobre multiplicadores que diferenciam os estados do ciclo econômico é muito escassa no Brasil. A grande dificuldade da literatura aplicada está na carência de estatísticas fiscais com séries relativamente longas, periodicidade adequada (trimestral, mensal, etc.) e cobertura das três esferas de governo ${ }^{11}$. Não por acaso, somente foi possível encontrar dois estudos que adotam modelos VAR com mudança de regime (Markok Switching) para investigar se os multiplicadores fiscais variam de acordo com alterações do estado da economia no Brasil (Pires, 2014; Castelo-Branco; Lima; Paula, 2015).

As principais conclusões de Pires (2014) são que os multiplicadores fiscais não possuem comportamento idêntico nos regimes de diferentes estados da economia e que a volatilidade é mais importante do que a média de crescimento na determinação desses regimes. Esse estudo não consegue calcular multiplicadores fiscais para o regime de alta volatilidade, mas obtém resultados significativos em períodos de baixa volatilidade, encontrando multiplicadores dos investimentos públicos situados entre 1,4 e 1,7 e multiplicadores do consumo do governo não significativos. Semelhantemente, Castelo-Branco, Lima e Paula (2015) concluem que choques nos investimentos públicos resultam em maior resposta do PIB do que os choques do consumo do governo. Contudo, seus resultados não sugerem maiores multiplicadores fiscais em regimes com maior variância, contrariamente ao resultado mais comum encontrado na literatura internacional.

Cabe observar que estes dois estudos fazem uso de informações trimestrais: Pires (2014) nos anos 1996-2012 (cerca de 60 observações) e Castelo-Branco, Lima e Paula (2015) um período ainda mais restrito nos anos 1999-2012. Podendo-se concluir que ambos os estudos compartilham um problema inevitável de amostra muito curta e convergem nos resultados de

(11) Atualmente, as estatísticas trimestrais oficiais divulgadas pela Secretaria do Tesouro Nacional (STN) estão restritas ao período a partir de 2010 ou 25 observações que é uma amostra muito curta para exercícios econométricos. Disponíveis em: http://www.tesouro.fazenda.gov.br/-/estatisticas-de-financas-publicas. 
multiplicadores fiscais dos investimentos maiores do que dos gastos correntes, mas são inconclusivos em relação aos efeitos sobre o ciclo econômico. Sugerindo-se que há um longo percurso a ser percorrido em termos de análises de multiplicadores fiscais no país.

O presente artigo baseia-se nos procedimentos de estimação de Auerbach e Gorodnichenko (2012), com algumas adaptações para os dados mensais brasileiros no período 2002-2015 que totaliza 168 observações. Faz-se uso das séries de investimentos públicos (IP) de Orair (2016), das receitas tributárias (CTB) de Orair et al. (2013) e do indicador mensal do PIB do Bacen ${ }^{12}$. Todas as variáveis foram dessazonalizadas via ARIMA x-13 e introduzidas em log no modelo STVAR descrito pelas equações 1 a 5 . Para calcular a variável $z_{t}$ tomou-se a média móvel da taxa de crescimento do PIB no período de seis meses ${ }^{13}$ - admitindo-se implicitamente que a recessão pode ser definida por uma contração geral na atividade econômica por dois trimestres. Essa variável foi normalizada e em seguida transformada, segundo a equação 4 , para obter a variável $F\left(z_{t}\right)$ no Gráfico 3 que, de maneira simplificada, pode ser interpretada como a probabilidade de se estar em uma recessão.

Gráfico 3

Recessões segundo a datação do Codace e variável $F(z)$

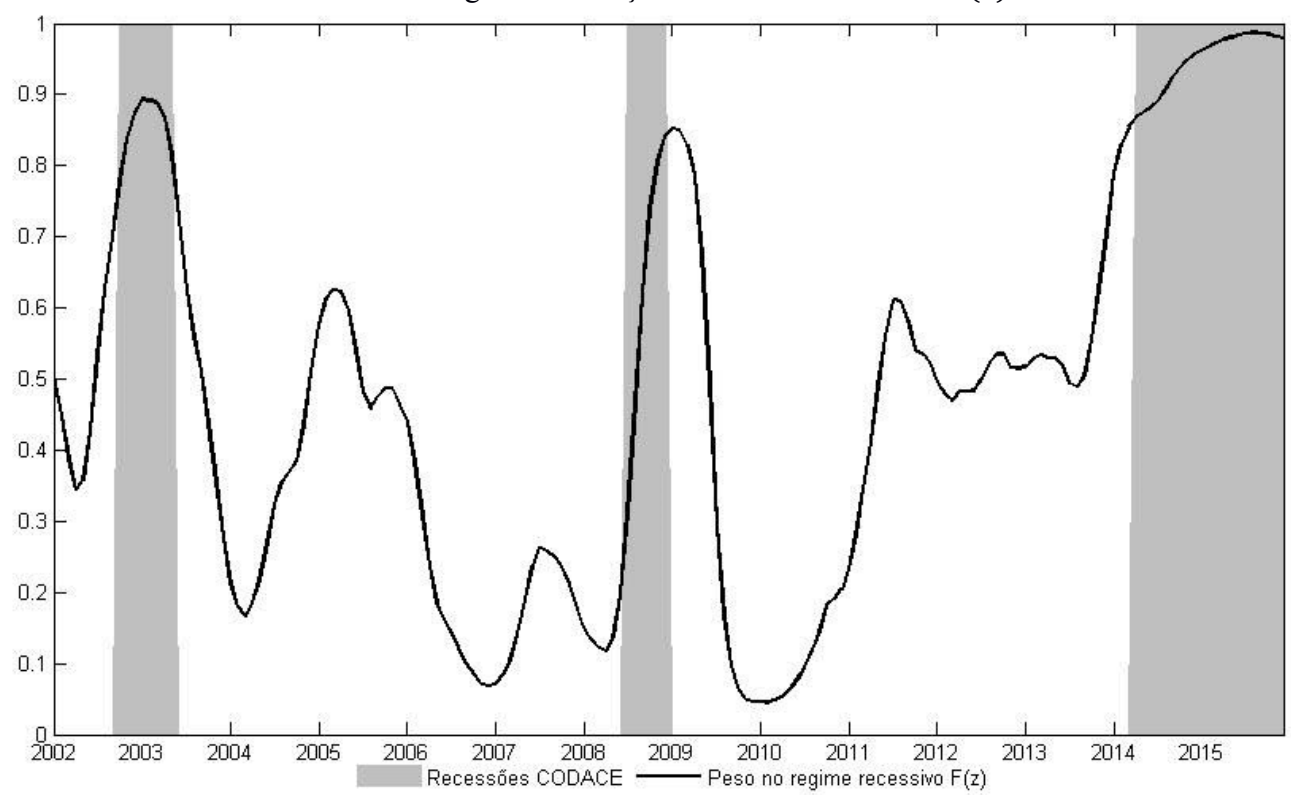

Notas: ${ }^{1}$ As áreas sombreadas mostram as recessões definidas pela Codace, enquanto que a linha negra demonstra a dinâmica de $F(z)$.

Elaboração dos autores.

(12) No caso dos investimentos públicos, essas séries cobrem os meses de janeiro de 1995 a dezembro de 2015 e são aproximações para os totais investidos pelo governo geral e empresas estatais federais. No entanto, as informações mensais da carga tributária estão restritas aos anos de 1995 a 2001.

(13) Considera-se a taxa real de crescimento do trimestre em relação ao trimestre do ano anterior. 
Investimento público no Brasil e suas relações com ciclo econômico e regime fiscal

De acordo com o Comitê de Datação de Ciclos Econômicos (Codace) do Instituto Brasileiro de Economia da Fundação Getúlio Vargas (IBRE/FGV), que tem como finalidade estabelecer cronologias de referência para os ciclos econômicos brasileiros, a economia brasileira esteve em recessão em aproximadamente $20 \%$ do período de 2002 a 2015 . Tal qual em Auerbach e Gorodnichenko (2012), foi definido que a economia está em recessão se $F\left(z_{t}\right)>0,8$. Para que a variável de transição esteja condizente com a datação do Codace, a calibragem do parâmetro $\gamma$ foi realizada respeitando o critério: $P\left(F\left(z_{t}\right)>0,8\right)=0,2$. O gráfico 3 permite comparar essa datação do Codace com a evolução da variável $F\left(z_{t}\right)$ e mostra uma aderência bastante razoável: com exceção dos primeiros meses da crise de 2008 , há uma coincidência entre os períodos também identificados como recessão pelo comitê do IBRE/FGV.

Uma das maiores vantagens da metodologia de transição suave em relação às abordagens que estimam cada regime em separado (isto é, abordagens com respostas binárias para recessão e expansão) é que nestas últimas pode haver um número excessivamente reduzido de informações em um regime particular, sobretudo nos regimes recessivos que são menos frequentes, e isto pode tornar as estimativas imprecisas e instáveis. O STVAR utiliza mais informações ao explorar a variação no grau (ou "probabilidade") em que se encontra em determinado regime, de modo que estimação e inferência para cada regime são baseadas em um conjunto maior de observações. Essa propriedade é particularmente útil para o caso brasileiro com reduzido número de observações disponíveis.

Porém, antes de serem apresentados os resultados, é importante esclarecer que o propósito deste exercício econométrico não é avaliar a hipótese de que o investimento público seja a única (e nem mesmo a principal) variável explicativa da dinâmica do PIB. Sem dúvida, o desempenho do produto é afetado por múltiplas variáveis e complexas interações entre elas - sendo que algumas destas variáveis, como o crédito, tiveram comportamento potencialmente mais favorável ao desempenho do produto -, as quais não são contempladas de maneira exaustiva pelo modelo econométrico. $\mathrm{O}$ exercício econométrico enfrenta o dilema clássico entre explicabilidade e previsibilidade e a inclusão destas potenciais variáveis traria à tona uma série de questões não triviais de identificação e de perda de graus de liberdade em uma modelagem que já enfrenta um problema de pequeno tamanho da amostra. Por conseguinte, a opção metodológica deste artigo é por uma estratégia de pesquisa seguindo a especificação básica do estudo de referência de Auerbach e Gorodnichenko (2012), que preserva os graus de liberdade do modelo e permite responder ao questionamento principal do trabalho sobre a sensibilidade do produto frente aos choques do investimento público, além de viabilizar comparações internacionais. De todo modo, seus resultados devem ser interpretados com cautela e estão longe de afirmar que os investimentos públicos tenham sido a única causa e nem sequer a principal causa do desempenho econômico no período.

\subsection{Estimação de multiplicadores fiscais: resultados}

O Gráfico 4 reporta as funções de impulso-resposta para um choque de R \$ 1,00 no investimento público. Os gráficos ditam o comportamento das variáveis durante um período de 
48 meses após o choque. A primeira coluna inclui no gráfico o intervalo de confiança de $90 \%$ da resposta do modelo linear, ao passo que a segunda e terceira, dos modelos recessivo e expansivo, respectivamente.

Gráfico 4

Funções de impulso-resposta no modelo linear, recessões e expansões
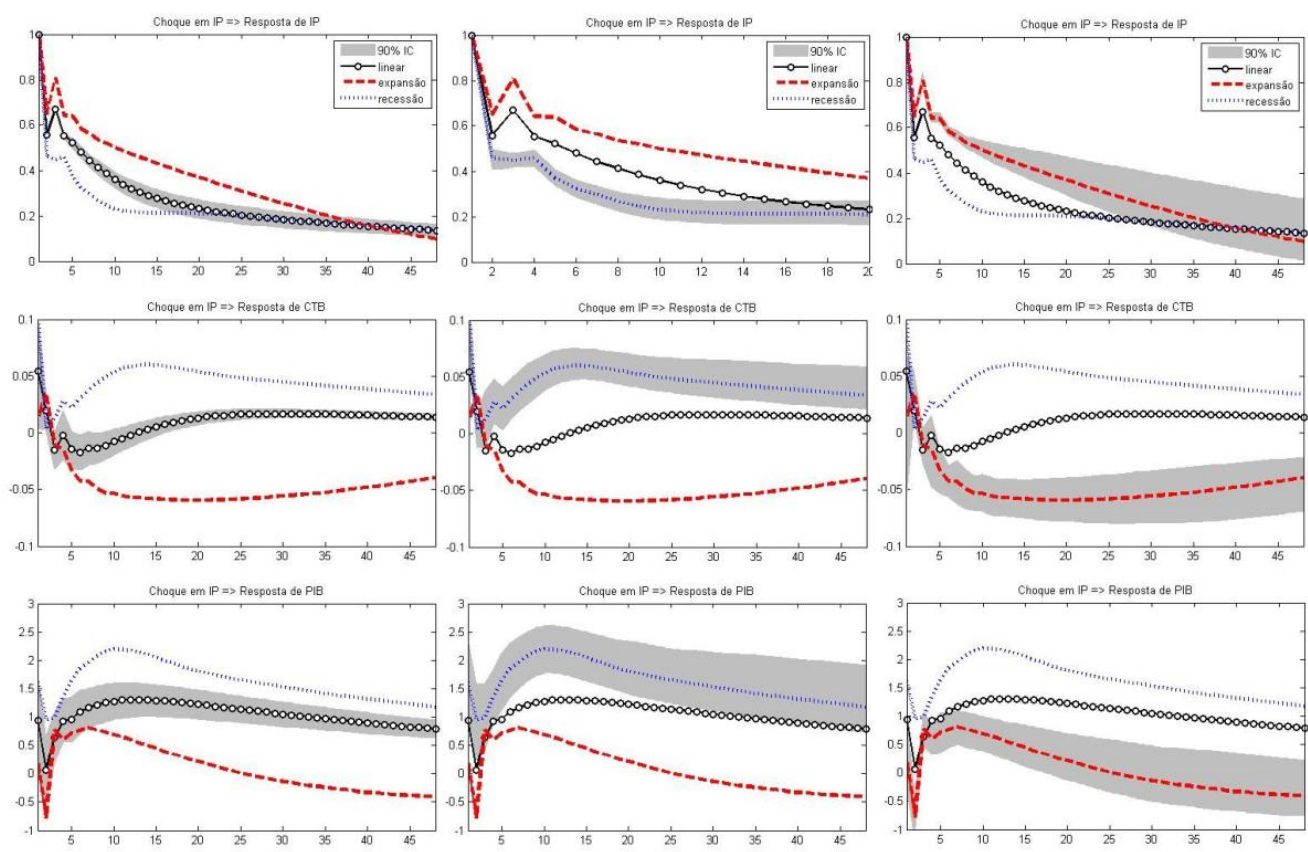

Notas: ${ }^{1}$ As figuras mostram as funções de impulso-resposta a um aumento de $\mathrm{R} \$ 1$ na variável de interesse. A região sombreada é o intervalo de confiança de $90 \%$.

Elaboração dos autores.

Os resultados corroboram as evidências encontradas na literatura internacional de que os multiplicadores fiscais diferem de acordo com os regimes recessivo/expansivo. As respostas do produto a choques do investimento no modelo não linear apresentam uma dinâmica similar (em formato hump-shapped), porém possuem níveis distintos: o impacto é em média 1,5 maior no regime recessivo em comparação com o regime expansivo. A resposta do produto em recessões (suficientemente) fortes é superior à unidade, persistente (estatisticamente significante durante todo o período de análise de 48 meses) e chega a alcançar valores elevados (próximos ou superiores a 2 no período de maior impacto de 3 a 5 trimestres). Por sua vez, a resposta do produto nas expansões (suficientemente) fortes sempre está abaixo da unidade e é pouco persistente (significativa apenas do $3^{\circ}$ ao $17^{\circ}$ mês).

Com intuito de clarificar essa análise, a primeira coluna da Tabela 2 traz o impacto máximo sobre o produto (e respectivo erro-padrão na segunda coluna), o qual é amplamente adotado por Blanchard e Perotti (2002) como medida de multiplicador fiscal. A terceira coluna 
Investimento público no Brasil e suas relações com ciclo econômico e regime fiscal

reporta a razão entre a resposta do produto (frente ao choque da despesa) e a resposta da despesa (frente ao choque da própria despesa), a qual é utilizada por Woodford (2011), uma vez que se argumenta que o tamanho do multiplicador fiscal depende da persistência dos choques fiscais. Pela tabela, pode-se verificar que os multiplicadores fiscais no regime recessivo são consideravelmente superiores aos do regime expansivo. Por exemplo, o multiplicador em recessões (suficientemente) fortes foi estimado em 2,2 no impacto máximo e em 0,8 nas expansões (suficientemente) fortes.

Cabe aqui, entretanto, advertir que os multiplicadores do modelo não linear são considerados extremos. Em geral, a economia encontra-se transitando entre regimes expansivos e recessivos. Por isto, as diferenças entre multiplicadores são superestimadas devido à pressuposição de que os regimes não mudam e pelo fato de considerar uma configuração com expansões e recessões fortes. Logo, não se deve prender muito ao valor pontual em si, mas sim à direção das funções de impulso-resposta. O mais razoável é admitir que, ao longo do tempo, os multiplicadores dos investimentos públicos assumam valores intermediários aos extremos. Algo que é consistente com o multiplicador de impacto máximo de 1,3 no modelo linear, sendo que a resposta do produto ao choque do investimento nesse modelo também se mostrou persistente convergindo para 0,8 ao longo de quatro anos.

Tabela 2

Multiplicadores Fiscais

\begin{tabular}{|c|c|c|c|c|}
\hline & \multicolumn{2}{|c|}{$\max _{h=1, \ldots, 48} Y_{h}$} & $\sum_{h=1}^{48} Y_{h} / \Sigma$ & ${ }_{1} g_{h}$ \\
\hline & Estimativa pontual & Erro Padrão & Estimativa pontual & Erro Padrão \\
\hline Linear & 1,3038 & 0,1957 & 3,8399 & 0,1466 \\
\hline Expansão & 0,8102 & 0,1783 & 0,2409 & 0,2339 \\
\hline Recessão & 2,1937 & 0,2664 & 7,0177 & 0,3005 \\
\hline
\end{tabular}

Fonte: Elaboração dos autores.

Em relação à resposta das receitas tributárias ao choque do investimento público, esta também mostrou distinção entre regimes: para o período recessivo, após uma moderada queda nos primeiros meses, a trajetória torna-se ligeiramente positiva e persistente ao longo do tempo; enquanto que o contrário ocorre no regime expansivo, quando após os primeiros meses ela fica ligeiramente negativa e mantém-se persistente. Pode-se concluir, portanto, que a arrecadação responde positivamente ao choque dos investimentos no regime recessivo, mas não no regime expansivo.

Sobre este último ponto, cabe observar que as dinâmicas das funções de impulsoresposta aos choques do investimento público, tanto para as receitas tributárias quanto para o produto, são semelhantes às encontradas na economia norte-americana por Auerbach e Gorodnichenko (2012). Estes autores também chegam ao resultado de que a resposta das receitas tributárias é positiva no regime recessivo e não no regime expansivo, diferença que é 
consistente com a resposta automática da arrecadação às mudanças no produto. Dito de outro modo, a existência de uma relação mais direta entre a arrecadação e o produto tende a fazer com que, nos regimes (fortemente) recessivos, a resposta positiva e persistente do produto se traduza em uma resposta positiva e persistente da arrecadação, assim como nos regimes (fortemente) expansivos, quando a resposta ligeiramente positiva e pouco persistente do produto (que perdura por alguns meses e depois fica inclusive negativa) também se reflete em um padrão de resposta semelhante da arrecadação. Entretanto, mais uma vez é preciso advertir que as funções de impulso-resposta do modelo não linear devem ser consideradas situações extremas com configurações de fortes recessões/expansões e que não se verificam por sucessivos períodos de tempo já que a economia encontra-se transitando entre regimes. Por isto, uma interpretação mais adequada é a de que tanto o produto quanto a arrecadação respondem de maneira mais positiva e persistente aos choques do investimento público nos períodos recessivos e estas respostas tendem a ser menores e pouco persistentes nas expansões.

Por um lado, esses resultados dão subsídios ao uso do investimento público como instrumento de política anticíclica, no sentido de que pode ser um instrumento de estímulo ao crescimento durante períodos recessivos. Ao mesmo tempo em que sugere cautela já que o mesmo instrumento não se mostra tão eficiente em períodos expansivos. Por outro lado, os mesmos resultados parecem indicar que a retração da taxa de investimentos públicos, em conjunturas de desaceleração econômica como em 2011-2014 ou em forte recessão como em 2015, quando os multiplicadores assumem seus valores mais elevados, tem fortes repercussões negativas e contribui para a deterioração do cenário econômico.

\section{Hipóteses explicativas para a queda recente da taxa de investimentos}

Além das repercussões da queda da taxa de investimentos sobre a atividade econômica no período 2011-2015, outro aspecto relevante a ser analisado diz respeito aos fatores que estão por trás desta queda. O propósito desta seção é justamente lançar algumas hipóteses explicativas para esse fenômeno e na próxima seção aprofundaremos a análise sobre uma delas.

\subsection{Condicionantes institucionais}

Uma primeira hipótese é que a dinâmica do investimento público foi influenciada menos pela questão orçamentária e mais pelas amarras institucionais, como problemas de gestão do governo ou questões ambientais e judiciais. É notório que o marco institucional impõe grandes obstáculos, sobretudo após a desarticulação das estruturas que deram suporte aos investimentos no período desenvolvimentista.

No entanto, não se deve desconsiderar que inúmeras ações voltadas à minoração dos obstáculos institucionais foram adotadas desde 2005 e inclusive favoreceram a retomada dos investimentos nos anos 2006-2010 (contração e capacitação de pessoal, esforços de coordenação entre órgãos do governo, recriação de instâncias de planejamento, retomada de planos estratégicos etc.). Além disso, o propósito aqui não é buscar uma explicação para o 
Investimento público no Brasil e suas relações com ciclo econômico e regime fiscal

baixo patamar da taxa de investimento público no Brasil e, sim, para a inflexão na sua trajetória, que vinha crescendo e passou a cair a partir de 2011. Para explicar essa reversão, seria necessário que os obstáculos institucionais tivessem se agravado demasiadamente durante um curto período de tempo a ponto de fazer com que a taxa de investimentos nos anos 2011-2015 retomasse níveis semelhantes aos de meados da década de 1990, algo que carece de evidências.

\subsection{Condicionantes externos e financeiros}

Uma segunda hipótese explicativa diz respeito ao papel dos condicionantes externos e financeiros na fase de grande recessão que sucedeu a crise internacional de 2008. A conjuntura internacional desfavorável levou à deterioração das condições de liquidez nos mercados financeiros e à revisão de projetos de investimentos em escala global. Na direção contrária, o governo federal implementou uma estratégia anticíclica de enfrentamento do cenário adverso, dando continuidade ao expansionismo fiscal iniciado em 2005, por meio de medidas como a ampliação da oferta de crédito doméstico pelos bancos públicos e a flexibilização das restrições à tomada de crédito pelos governos regionais e empresas estatais.

Desse modo, a ação estatal anticíclica permitiu contornar a maior parte dos obstáculos externos e financeiros aos investimentos públicos. No âmbito dos governos regionais, por exemplo, os anos 2011-2014 coincidiram com o auge de um período de retomada de endividamento junto a organismos multilaterais e bancos públicos, em que o principal destino dos recursos foi financiar projetos de investimentos ${ }^{14}$. Tampouco existem indícios de forte intensificação nas restrições ao endividamento do governo central. Isso parece ter ocorrido de maneira mais evidente apenas no âmbito de empresas estatais como a Petrobras e a Eletrobras, nos anos 2014 e 2015, que, devido à deterioração das suas condições financeiras, tiveram o acesso ao mercado de crédito dificultado ${ }^{15}$. Em suma, os obstáculos financeiros emergiram de maneira muito localizada e não fornecem uma explicação completa para a inflexão dos investimentos públicos a partir de 2011 .

\subsection{Reorientação da estratégia governamental}

A terceira hipótese explicativa é que houve uma revisão na estratégia governamental que passou a apostar mais no setor privado e menos no investimento público. Na virada da década de 2010 emergiu um diagnóstico, por uma parcela do governo, de que vários dos grandes projetos de investimentos públicos continham deficiências e atrasos excessivos nos seus cronogramas. Esse diagnóstico parece ter influenciado para que, diante da nova

(14) Mora (2016) e Orair et al. (2016) analisam o processo de retomada do crédito bancário e externo que contou com o aval do governo central. É apenas com a inflexão da política fiscal em 2015 que o governo central voltou a impor restrições mais fortes à tomada de crédito pelos governos regionais.

(15) As condições financeiras dessas empresas se deterioraram rapidamente influenciadas por condicionantes externos e internos (por exemplo, colapso do preço internacional do petróleo e compressão das tarifas de energia elétrica e dos preços domésticos dos derivados do petróleo). Afonso, Vilma e Fajardo (2015) e Cerqueira (2016) analisam esse fenômeno com maior profundidade e suas repercussões sobre os investimentos, além de apresentarem análises sobre os investimentos do governo geral. 
desaceleração econômica verificada a partir de 2011, o governo tenha optado por uma estratégia de enfrentamento baseada principalmente em estímulos como subsídios, desonerações, reduções de tarifas e um plano de concessões em infraestrutura, prevendo maior presença do setor privado. O pressuposto básico da estratégia era que os investimentos privados reagiriam mais rapidamente do que os investimentos públicos ${ }^{16}$.

Essa hipótese de reorientação na estratégia governamental tampouco é suficiente para explicar a inflexão para uma trajetória de queda da taxa de investimentos públicos. A aposta mais incisiva no setor privado não necessariamente exige uma retração dos investimentos públicos. No próprio discurso governamental sempre predominou uma retórica acomodativa, argumentando-se em favor da necessidade de se aprimorar o planejamento e a execução dos projetos para dar continuidade à retomada dos investimentos públicos, assim como seu caráter complementar em relação aos investimentos privados. Assim, é pouco razoável admitir que houve uma ação deliberada no sentido de promover uma inflexão na tendência de crescimento dos investimentos públicos.

\subsection{Retorno dos constrangimentos orçamentários}

Resumindo, as hipóteses explicativas delineadas nas subseções 4.1 a 4.3 são relevantes, mas não explicam integralmente a dinâmica dos investimentos públicos. Uma hipótese complementar diz respeito à paralisia de instâncias governamentais, ocasionada por fatores como instabilidade política desde 2013 e denúncias de irregularidade ${ }^{17}$. Infelizmente, o impacto desses fatores sobre os investimentos públicos é de difícil avaliação.

Por fim, a hipótese central deste trabalho é que os constrangimentos orçamentários aos investimentos públicos foram intensificados após 2011. À primeira vista, essa hipótese pode soar paradoxal porque a interrupção da retomada dos investimentos públicos e o início do seu retrocesso ocorreu durante um período de expansionismo fiscal (2011-2014). Para melhor compreensão desse ponto, será necessário proceder a uma análise mais geral da política fiscal no Brasil explorando as relações dos investimentos públicos com o regime fiscal. Este será o propósito da próxima seção cujo foco recairá especificamente sobre o governo central.

Antes de prosseguir, entretanto, cabe fazer duas advertências. Primeiramente, há que se ressaltar que a discussão sobre as restrições financeiras aos investimentos públicos deve levar em consideração o arcabouço fiscal vigente no país. O regime de metas primárias restringe o acesso ao endividamento e reduz os graus de liberdade da política fiscal ao estabelecer limites aos agregados orçamentários e, sobretudo, àquelas despesas que, como os investimentos, possuem uma natureza essencialmente discricionária. Mesmo que do ponto de

(16) Afonso e Gobetti (2015) e Gobetti e Orair (2015) desenvolvem argumentos semelhantes.

(17) Por exemplo, as denúncias de irregularidades no Departamento Nacional de Infraestrutura de Transportes (DNIT) em 2011, que desorganizaram temporariamente o órgão e levaram a uma reforma nos instrumentos de contratação de obras públicas, e que se repetiriam com maior gravidade na Operação Lava-Jato em 2014 e 2015, que afetou importantes instâncias responsáveis pelos investimentos, como as empresas estatais e as grandes empreiteiras. 
Investimento público no Brasil e suas relações com ciclo econômico e regime fiscal

vista teórico a restrição mais geral aos investimentos esteja relacionada à debilidade do mercado de financiamento de longo prazo no país, na prática o regime de metas reduz essa discussão à questão dos constrangimentos do orçamento primário.

Em segundo lugar, é preciso advertir que as diversas hipóteses explicativas para a queda da taxa de investimentos públicos a partir de 2011 não são excludentes. Como será analisado na sequência, o custo fiscal da estratégia de estímulo aos investimentos privados por subsídios e desonerações, bem como seu malogro em termos de recuperar o crescimento econômico, é um dos fatores responsáveis, mas não o único, pela intensificação dos constrangimentos orçamentários aos investimentos.

\section{Regime fiscal, orientação da política econômica e investimentos públicos}

O regime fiscal baseado em metas anuais de superavit primário está em vigor no Brasil desde 1999, mas, ao longo desse período, esteve sujeito a diversas tensões, passou por flexibilizações e acomodou diferentes orientações da política fiscal. Durante a fase contracionista do ciclo de médio prazo da política fiscal (1999-2005), as metas foram progressivamente aumentadas, e os resultados primários saíram de valores aproximadamente nulos (em média, -0,2\% do PIB no quadriênio 1995-1998) para alcançar um superavit superior a 4,0\% do PIB. Esse processo de ajustamento se apoiou no acréscimo da carga tributária de 6,6 p.p. no PIB e em outro 1,3 p.p. de queda dos investimentos públicos, e também acomodou o acréscimo de outras despesas como os benefícios sociais.

O quadro se modificou com a reorientação da política fiscal para uma fase de flexibilização, quando uma série de instrumentos foram introduzidos no regime de metas com o intuito de gerar espaço fiscal. O primeiro desses instrumentos foi o Projeto Piloto de Investimentos (PPI), criado em 2005 e depois ampliado com o lançamento do PAC. O PPI serviu para introduzir a ideia de que alguns investimentos precisariam receber tratamento fiscal diferenciado por ensejarem um processo virtuoso de autofinanciamento, e, por conseguinte, poderiam ser deduzidos da meta fiscal. A concepção do PPI seguia recomendações de organismos multilaterais para retirar o viés anti-investimento de regras numéricas muito rígidas, sendo que a opção brasileira apenas previa a dedução da meta fiscal de uma carteira bem seletiva de projetos e não um orçamento de capital em separado.

O PAC contribuiu ao deslanchar um conjunto de projetos na área de infraestrutura e ampliar substancialmente a margem de dedução. No ano de 2009, por exemplo, a margem de dedução de investimentos quase dobrou, de $\mathrm{R} \$ 15,6$ bilhões para $\mathrm{R} \$ 28,5$ bilhões, com a mudança do PPI para o PAC. Em contrapartida, os critérios de enquadramento foram flexibilizados no PAC, e os projetos se afastaram gradualmente dos investimentos públicos propriamente ditos. Voltaremos a esse ponto mais adiante.

Um segundo instrumento de flexibilização foi a exclusão de empresas estatais federais da meta fiscal, com intuito de liberá-las de constrangimentos orçamentários para que viabilizassem seus planos de investimentos. Simultaneamente, a meta de resultado primário foi 
sendo reduzida: recalculada de 4,25\% para 3,8\%, após a divulgação da nova série do PIB pelo IBGE em 2007, que elevou o denominador da relação entre resultado primário e PIB; para $3,3 \%$, com a retirada das empresas do Grupo Petrobras em 2009; e para 3,1\%, com a retirada das empresas do Grupo Eletrobras em $2010^{18}$.

Tabela 3

Metas e valores realizados do superavit primário do setor público (2003-2016)

(Em participação percentual do PIB)

\begin{tabular}{|c|c|c|c|c|c|c|c|c|c|}
\hline Ano & $\begin{array}{c}\text { Meta de } \\
\text { superavit } \\
\text { (A) }\end{array}$ & $\begin{array}{l}\text { Margem } \\
\text { de } \\
\text { dedução } \\
\text { PPI/PAC } \\
\text { (B) }\end{array}$ & $\begin{array}{c}\mathrm{PPI} / \mathrm{PAC} \\
\text { executado } \\
\text { (C) }\end{array}$ & $\begin{array}{c}\text { Teto de } \\
\text { superavit } \\
\text { pós- } \\
\text { dedução } \\
\text { PPI/PAC } \\
(\mathrm{D}=\mathrm{A}- \\
\mathrm{B})\end{array}$ & $\begin{array}{c}\text { Superavit } \\
\text { realizado }^{2} \\
\text { (E) }\end{array}$ & $\begin{array}{l}\text { Excedente } \\
(\mathrm{F}=\mathrm{E}-\mathrm{D})\end{array}$ & $\begin{array}{l}\text { Ampliação } \\
\text { da margem } \\
\text { de deduções } \\
\text { (G) }\end{array}$ & $\begin{array}{c}\text { Teto de } \\
\text { superavit } \\
\text { pela } \\
\text { legislação } \\
(\mathrm{H}=\mathrm{D}- \\
\text { G) }\end{array}$ & $\begin{array}{c}\text { Fundo } \\
\text { Soberano e } \\
\text { Cessão } \\
\text { onerosa (I) }\end{array}$ \\
\hline 2003 & $4,25 \%$ & - & - & $4,25 \%$ & $4,37 \%$ & $0,12 \%$ & - & $4,25 \%$ & - \\
\hline 2004 & $4,25 \%$ & - & - & $4,25 \%$ & $4,58 \%$ & $0,33 \%$ & - & $4,25 \%$ & - \\
\hline 2005 & $4,25 \%$ & $0,14 \%$ & $0,06 \%$ & $4,11 \%$ & $4,83 \%$ & $0,72 \%$ & - & $4,11 \%$ & - \\
\hline 2006 & $4,25 \%$ & $0,15 \%$ & $0,14 \%$ & $4,10 \%$ & $4,37 \%$ & $0,27 \%$ & - & $4,10 \%$ & - \\
\hline 2007 & $4,25 \%$ & $0,20 \%$ & $0,23 \%$ & $4,05 \%$ & $4,50 \%$ & $0,45 \%$ & - & $4,05 \%$ & - \\
\hline 2008 & $3,80 \%$ & $0,48 \%$ & $0,27 \%$ & $3,32 \%$ & $4,56 \%$ & $1,24 \%$ & - & $3,32 \%$ & $-0,49 \%$ \\
\hline 2009 & $2,50 \%$ & $0,90 \%$ & $0,57 \%$ & $1,60 \%$ & $2,05 \%$ & $0,45 \%$ & - & $1,60 \%$ & - \\
\hline 2010 & $3,30 \%$ & $0,67 \%$ & $0,65 \%$ & $2,63 \%$ & $2,07 \%$ & $-0,57 \%$ & - & $2,63 \%$ & $0,94 \%$ \\
\hline 2011 & $3,30 \%$ & $0,84 \%$ & $0,74 \%$ & $2,46 \%$ & $3,38 \%$ & $0,93 \%$ & - & $2,46 \%$ & - \\
\hline 2012 & $3,10 \%$ & $0,90 \%$ & $0,87 \%$ & $2,20 \%$ & $2,05 \%$ & $-0,15 \%$ & - & $2,20 \%$ & $0,27 \%$ \\
\hline 2013 & $3,10 \%$ & $0,88 \%$ & $0,89 \%$ & $2,22 \%$ & $1,82 \%$ & $-0,40 \%$ & $0,42 \%$ & $1,80 \%$ & - \\
\hline 2014 & $3,10 \%$ & $1,07 \%$ & $1,07 \%$ & $2,03 \%$ & $-0,60 \%$ & $-2,63 \%$ & Sem limite & Sem teto & - \\
\hline 2015 & $-0,85 \%$ & - & $0,82 \%$ & $-0,85 \%$ & $-1,92 \%$ & $-1,07 \%$ & $1,18 \%$ & $-2,03 \%$ & $0,01 \%$ \\
\hline 2016 & $-2,64 \%$ & - & nd & $-2,64 \%$ & nd & $\mathrm{Nd}$ & - & $-2,64 \%$ & - \\
\hline
\end{tabular}

Obs.: ${ }^{1}$ Consideram-se os valores do PIB previstos nas leis orçamentárias que servem de referência para o cumprimento da meta e não os valores atualizados.

${ }^{2}$ Exclui os efeitos das triangulações de recursos no Fundo Soberano (2008, 2012 e 2015) e nas operações de cessão onerosa e capitalização da Petrobras (2010).

${ }^{3}$ Considera desonerações tributárias, frustrações de receitas e passivos quitados junto a fundos e bancos públicos.

Fonte: Elaboração dos autores a partir das informações de leis orçamentárias e relatórios fiscais.

O resultado das flexibilizações foi que o teto de superavit para fins de cumprimento da legislação reduziu-se de 4,25\% em 2004 para 2,63\% do PIB em 2010, como se pode observar

(18) Além de uma redução temporária para 2,5\% do PIB em 2009, com o intuito de acomodar o pacote de medidas anticíclicas e os efeitos do contágio da crise internacional no Brasil. 
Investimento público no Brasil e suas relações com ciclo econômico e regime fiscal

na Tabela 3. Essa redução, juntamente com o maior dinamismo econômico do período, que impulsionou as receitas, abriu espaço fiscal, que foi canalizado predominantemente para investimentos públicos. Entre 2005 e 2010, o resultado primário do governo geral caiu de 3,7\% para 2,6\% do $\mathrm{PIB}^{19}$, sua taxa de investimentos acresceu em um montante da mesma magnitude, de $1,1 \%$ p.p. do PIB, e a taxa de investimentos das empresas estatais federais liberadas do cumprimento de metas fiscais acresceu mais 0,9 p.p. do PIB.

$\mathrm{O}$ fato de o espaço fiscal ter sido canalizado predominantemente para investimentos no período 2006-2010 não significa que essas despesas foram as únicas que cresceram e nem mesmo as que mais cresceram em termos absolutos. Ao contrário, o principal fator de expansão das despesas primárias está relacionado à dinâmica dos gastos sociais e, mais precisamente, aos benefícios sociais (assistenciais e previdenciários), que representam cerca de metade do orçamento primário federal e crescem a taxas elevadas e muito estáveis desde a década de 1990, como se pode observar na tabela 4. Esses gastos sociais respondem, em grande medida, a pressões estruturais em favor de transferências redistributivas e da construção de um projeto de estado de bem-estar social, com ampliação do acesso aos serviços sociais básicos pela população, que remontam pelo menos à renovação do contrato social após a Constituição Federal de 1988.

Quando analisamos em perspectiva os mais de 17 anos do regime de metas primárias, as principais mudanças encontram-se na composição da política fiscal e na trajetória do resultado primário e não tanto no ritmo de crescimento das despesas primárias que, impulsionadas pelos benefícios sociais, cresceram a taxas semelhantes ao longo dos diversos subperíodos na Tabela 4. A consolidação fiscal do período 1999-2005 exigiu aumentos legislados da carga tributária e queda na taxa de investimentos públicos para alcançar o duplo propósito de acomodar o gasto social e canalizar recursos para ampliar o superavit primário.

No período subsequente de flexibilização fiscal (2006-2014), os resultados primários foram gradualmente reduzidos, e a arrecadação acompanhou de maneira mais próxima o ritmo de crescimento do PIB, com a carga tributária mantendo-se a relativamente estabilizada ${ }^{20}$. Outra distinção importante é que, durante o primeiro subperíodo da fase de flexibilização fiscal (2006-2010), a arrecadação acompanhou o ritmo mais acelerado de crescimento econômico e acomodou pressões do gasto social. A combinação entre flexibilizações nas metas primárias e maior dinamismo da arrecadação ampliou os graus de liberdade da política fiscal e criou espaço fiscal que foi canalizado predominantemente para os investimentos durante o subperíodo de expansionismo fiscal (2006-2010).

(19) Desconsiderando-se o resultado das empresas da Petrobras e da Eletrobras, que foram retiradas da meta, e a receita atípica da triangulação de recursos nas operações de cessão onerosa e capitalização da Petrobras em 2010.

(20) Como mostra Orair (2015), a carga tributária oscilou em torno de 33\% do PIB ao longo do decênio 2005-2014, mesmo sob predomínio das desonerações tributárias. Esse paradoxo é explicado pelas características do padrão de crescimento econômico, favoráveis à arrecadação, como a formalização do mercado de trabalho com expansão da massa salarial, o crescimento do volume de importações e, no período anterior à crise de 2008, um boom financeiro de lucros não operacionais e de ganhos de capital. 
Existem vários fatores por trás do maior dinamismo econômico desse período, mais notadamente o boom de liquidez e de preços de commodities anterior à crise internacional de 2008, que relaxou a restrição externa ao crescimento da economia brasileira. Não se deve negligenciar, contudo, a influência dos fatores domésticos, como a própria mudança na composição da política fiscal, mais favorável aos investimentos públicos, que cresceram a taxas superiores a dois dígitos, as mais elevadas entre os componentes das despesas na Tabela 4. Os multiplicadores dos investimentos públicos estimados na seção 3 deste artigo dão indícios nessa direção, cujos impactos máximos assumem valores entre 0,8 e 2,2 dependendo do estado do ciclo econômico.

Tabela 4

Crescimento das receitas e despesas primárias do governo central por períodos selecionados Taxa real de crescimento ao ano (1999-2015) ${ }^{1}$

$(\mathrm{Em} \%)$

\begin{tabular}{l|c|c|c|c|c}
\hline \multicolumn{1}{c|}{ Discriminação } & $1999-2002$ & $2003-2006$ & $2007-2010$ & $2011-2014$ & $2014-2015$ \\
\hline Receita total & $6,5 \%$ & $4,7 \%$ & $3,6 \%$ & $1,5 \%$ & $-6,0 \%$ \\
\hline Despesa total & $3,9 \%$ & $5,2 \%$ & $5,5 \%$ & $3,8 \%$ & $-2,9 \%$ \\
\hline Pessoal & $3,4 \%$ & $0,7 \%$ & $4,1 \%$ & $-0,3 \%$ & $1,8 \%$ \\
\hline Benefícios Sociais & $6,0 \%$ & $8,8 \%$ & $4,5 \%$ & $4,3 \%$ & $0,4 \%$ \\
\hline Subsídios & $-14,3 \%$ & $32,3 \%$ & $14,9 \%$ & $23,8 \%$ & $-10,3 \%$ \\
\hline Custeio & $2,9 \%$ & $3,6 \%$ & $4,8 \%$ & $4,7 \%$ & $-5,3 \%$ \\
\hline FBCF & $-4,2 \%$ & $2,3 \%$ & $24,0 \%$ & $0,3 \%$ & $-41,4 \%$ \\
\hline Outras despesas de capital & $2,9 \%$ & $-5,9 \%$ & $11,4 \%$ & $-2,5 \%$ & $-14,7 \%$ \\
\hline PIB & $2,3 \%$ & $3,5 \%$ & $4,6 \%$ & $2,2 \%$ & $-3,8 \%$ \\
\hline
\end{tabular}

Nota: ${ }^{1}$ Valores convertidos pelo deflator implícito do PIB.

Elaboração dos autores, com valores atualizados de Gobetti e Orair (2015).

Vale destacar que na maior parte desse período de bonança (2006-2010) havia um excedente orçamentário para fins de investimento, no sentido de que o resultado primário superava o teto permitido pela legislação caso fosse feito uso completo das deduções, e poucas vezes foi necessário recorrer às deduções do PPI/PAC porque os resultados primários normalmente superavam as metas (ver tabela 3). É justamente aí que ganha força a tese de que os constrangimentos orçamentários deixaram de ser um problema tão grande e que o baixo volume de investimento público deveria ser atribuído mais às amarras institucionais, como problemas de gestão do governo ou questões ambientais e judiciais ${ }^{21}$.

Esta hipótese, mesmo que seja relevante para explicar o baixo nível de execução de projetos específicos (principalmente nas grandes obras de infraestrutura), deve ser relativizada quando se deseja analisar as restrições orçamentárias ao agregado dos investimentos públicos.

(21) Tese defendida em Almeida (2009), por exemplo. 
Investimento público no Brasil e suas relações com ciclo econômico e regime fiscal

Basta observar que, nas duas primeiras vezes em que o governo fez uso da margem de dedução de investimentos para cumprir a meta fiscal (2009 e 2010), ela foi utilizada apenas parcialmente e sob intensas críticas. Na ocasião, o procedimento previsto na legislação foi interpretado como "contabilidade criativa" por diversos analistas da política fiscal, de maneira indistinta em relação a outras medidas que elevam artificialmente o resultado primário, e essa interpretação controversa teve ampla repercussão no debate público. Isso sugere a imposição de um constrangimento, senão do ponto de vista legal, ao menos de caráter pragmático, já que, na prática, evitava-se fazer amplo uso do excedente orçamentário para investimentos. O mais usual até 2010 foi o governo cumprir suas metas impondo contingenciamentos à base de despesas discricionárias, dentre elas os investimentos, e, apenas em caráter excepcional, deduzindo uma parcela da margem de investimentos da meta fiscal.

A principal hipótese desta seção do artigo é a de que o mecanismo de dedução dos investimentos prioritários, tal qual introduzido e operacionalizado no país, apenas flexibilizou parcial e temporariamente as restrições orçamentárias sem equacionar a tensão básica entre o objetivo de cumprir a meta fiscal e o de ampliar esses investimentos. As restrições orçamentárias persistiram em menor ou maior grau, tendo sido temporariamente relaxadas durante os anos 2006-2010, mas tornando-se mais agudas no período 2011-2014, quando a economia brasileira adentrou um novo período recessivo, e o espaço fiscal para investimentos reduziu-se bruscamente.

Cabe aqui destacar três fatores responsáveis pela redução do espaço fiscal para investimentos públicos no período 2011-2014. Primeiramente, o governo reorientou sua estratégia para priorizar desonerações e subsídios, sendo que esses últimos passaram a mostrar as mais elevadas taxas de crescimento entre os componentes das despesas primárias (tabela 4). A rápida expansão desses instrumentos insere-se em uma estratégia de reação à conjuntura econômica depressiva, sob o pressuposto de que, oferecendo-se estímulos suficientes ao setor privado, seria possível alavancar o investimento e retomar o crescimento. O custo fiscal da estratégia foi alto. O governo renunciou a volumes significativos de receitas, cujas desonerações instituídas mais que dobraram da média anual de $\mathrm{R} \$ 26,3$ bilhões nos anos 20062010 para R \$ 69,3 bilhões entre 2011-2014, injetou cerca de R \$ 17 bilhões por ano no programa Minha Casa Minha Vida (MCMV) e multiplicou os volumes de subsídios aos empréstimos do Banco Nacional de Desenvolvimento Social (BNDES) que alcançaram 29,1 bilhões em 2014. O resultado foi que a reação ficou limitada a setores específicos, sobretudo aqueles mais diretamente beneficiados, e a taxa agregada de investimentos privados não respondeu.

Em segundo lugar, a arrecadação desacelerou acompanhando a queda no ritmo de atividade econômica, além de ter sido influenciada pelo crescente volume de desonerações. Adicionalmente, ficou explícito o caráter rígido e inercial dos gastos sociais, que permaneceram crescendo a taxas muito semelhantes às do período anterior. No caso do governo central, o crescimento das receitas primárias se desacelerou de 3,6\% ao ano (a.a.) durante 20072010 para 1,5\% a.a. em 2011-2014, enquanto os benefícios sociais cresceram a taxas próximas a $4,5 \%$ a.a. em ambos os períodos (Tabela 4 ). 
Diante da conjuntura de baixo crescimento econômico e desaceleração das receitas, com manutenção do ritmo de expansão de parcela considerável das despesas (benefícios sociais) ou mesmo aceleração de algumas rubricas (subsídios), o cumprimento das metas de resultado primário somente seria factível por dois caminhos. O primeiro via contingenciamentos muito fortes sobre a pequena parcela restante de despesas discricionárias passíveis de serem comprimidas no curto prazo, inclusive os investimentos. A segunda alternativa seria recorrer a medidas artificiais como receitas não recorrentes ${ }^{22}$, postergação de pagamentos (ou pedaladas no jargão orçamentário) e ampliação da margem de despesas dedutíveis da meta.

Em 2010, os investimentos públicos alcançaram o auge do período histórico recente, e a meta foi cumprida com expressivas receitas não recorrentes, como a triangulação de recursos nas operações de cessão onerosa com simultânea capitalização da Petrobras. No ano de 2011 aconteceu o oposto: o governo anunciou que cumpriria a meta cheia de resultado primário, sem utilizar a margem de dedução, e interrompeu o processo de retomada dos investimentos públicos. Esse foi o último ano que se observou um excedente orçamentário para fins de investimentos (Tabela 3). O que se viu no período 2012-2014, quando o governo ainda relutava em modificar sua meta fiscal, mantida acima de 3\% do PIB, foi que ela seria formalmente cumprida, mediante sucessivas alterações na legislação, por um misto dos dois caminhos supracitados.

Em particular, a margem de deduções, ao longo do tempo, foi sendo ampliada e perdendo sua relação mais direta com os investimentos públicos prioritários. Por exemplo, o governo reclassificou despesas nas áreas de saúde, educação e segurança, que passaram a compor o PAC a partir de 2012; e em 2013-2014, ampliou a margem de dedução para contemplar desonerações tributárias. Até que, no ano de 2015, o governo propôs cumprir uma meta cheia de resultado primário, de $1,2 \%$ p.p. do PIB. A meta não se mostrou factível, e a legislação foi alterada, prevendo um déficit de 0,85\% p.p. e deduções de mais 1,18\% p.p., referentes à frustração de receitas e quitação de passivos junto aos bancos e fundos públicos. Novamente em 2016, o governo propôs uma meta inicial cheia de 0,5\% p.p. do PIB e alterou a legislação para um déficit de $2,64 \%$ do PIB, sendo que a redação final do projeto de lei que alterou a meta fiscal sequer faz referência ao mecanismo de dedução das despesas prioritárias de investimentos.

O próprio PAC teve critérios de enquadramento flexibilizados e acomodou crescente volume de despesas que não são investimentos propriamente ditos. Fazendo emergir uma situação paradoxal retratada na tabela 5: enquanto a FBCF do governo central permaneceu praticamente estagnada nos anos 2010-2014, os volumes de execução do PAC dobraram, influenciados por reclassificações e outras despesas como os subsídios do programa

(22) As receitas não recorrentes incluem receitas extraordinárias e contabilidade criativa, entre outras medidas. Ver Schettini et al. (2011). 
Investimento público no Brasil e suas relações com ciclo econômico e regime fiscal

$\mathrm{MCMV}^{23}$. Sintetizando, a margem de dedução, que era formada inicialmente por uma carteira seletiva de projetos prioritários de investimentos, foi gradualmente alterando sua composição e deixando de ter relação com investimentos prioritários. Até culminar no seu abandono no biênio 2015-2016.

Tabela 5

Despesas pagas do PPI/PAC (2006-2015)

(Em bilhões de R\$ de 2015 convertidos pelo IPCA)

\begin{tabular}{|c|c|c|c|c|c|c|c|c|c|c|c|c|c|}
\hline Discriminação & 2006 & 2007 & 2008 & 2009 & 2010 & 2011 & 2012 & 2013 & 2014 & 2015 & $\begin{array}{l}2006- \\
2010\end{array}$ & $\begin{array}{c}2010- \\
2014\end{array}$ & $\begin{array}{c}2014- \\
2015\end{array}$ \\
\hline PPI/PAC & 4,9 & 8,2 & 12,0 & 23,4 & 30,6 & 36,4 & 48,4 & 51,8 & 62,9 & 47,3 & $57,9 \%$ & $19,8 \%$ & $\begin{array}{c}- \\
24,9 \%\end{array}$ \\
\hline FBCF & 4,0 & 6,0 & 8,3 & 13,4 & 19,2 & 17,1 & 17,6 & 21,5 & 27,2 & 14,1 & $47,7 \%$ & $9,1 \%$ & $\begin{array}{c}- \\
48,1 \%\end{array}$ \\
\hline $\begin{array}{l}\text { Transferências aos } \\
\text { governos subnacionais }\end{array}$ & 0,6 & 1,0 & 3,2 & 6,5 & 8,3 & 7,8 & 15,2 & 9,7 & 12,9 & 8,3 & $90,1 \%$ & $11,7 \%$ & $\begin{array}{c}- \\
35,3 \%\end{array}$ \\
\hline $\begin{array}{l}\text { Minha Casa Minha } \\
\text { Vida }\end{array}$ & 0,0 & 0,0 & 0,0 & 0,0 & 2,2 & 10,0 & 13,9 & 16,4 & 19,0 & 20,7 & - & $71,9 \%$ & $9,0 \%$ \\
\hline Outras despesas & 0,3 & 1,3 & 0,5 & 3,5 & 0,9 & 1,5 & 1,7 & 4,2 & 3,9 & 4,1 & $38,4 \%$ & $43,1 \%$ & $6,7 \%$ \\
\hline Memo: FBCF Total & 15,1 & 18,5 & 21,0 & 28,7 & 40,5 & 36,1 & 32,2 & 37,1 & 43,2 & 25,0 & $27,9 \%$ & $1,7 \%$ & $\begin{array}{c}- \\
42,3 \%\end{array}$ \\
\hline
\end{tabular}

Elaboração dos autores, com dados do Sistema Integrado de Administração Financeira (Siafi).

Tal situação explicita a fragilidade do mecanismo introduzido no regime de metas primárias para conferir tratamento orçamentário diferenciado aos investimentos prioritários. Essa fragilidade, juntamente com a elevada rigidez que caracteriza a política fiscal brasileira, acaba por tornar os investimentos públicos muito vulneráveis no atual regime fiscal. Daí que a combinação da desaceleração das receitas com a manutenção do ritmo de expansão das despesas em um cenário de baixo crescimento econômico - o que se explica por um componente de caráter mais estrutural e inercial relacionado aos gastos sociais, que já vinham crescendo desde a década de 1990, ao qual se somaram novos gastos de subsídios e as renúncias de receitas na estratégia do governo de promover a retomada do crescimento via estímulos ao setor privado - tenha resultado inevitavelmente na brusca redução do espaço fiscal para investimentos no período 2011-2014.

O recurso às medidas artificiais para alcançar a meta fiscal (receitas não recorrentes, ampliação forçada da margem de deduções e postergações de pagamentos) acabaram funcionado como um instrumento nada transparente para conferir flexibilidade ao regime fiscal,

(23) Os valores da FBCF do governo central apresentados na tabela 5 são apurados pelo conceito de caixa e deflacionados pelo IPCA, diferindo um pouco daqueles vistos na tabela 1, sob competência (patrimonial) e convertidos pelo deflator implícito do PIB. 
não sendo sequer suficiente para evitar a imposição de maiores entraves orçamentários aos investimentos que contribuíram para sua estagnação e mesmo seu declínio no período em questão. Isso consolidou uma mudança na composição da política fiscal, com a passagem de um período cujo espaço fiscal criado pelas flexibilizações do regime de metas foi canalizado principalmente para investimentos (2006-2010) para um período de maior crescimento dos subsídios e das desonerações (2011-2014).

Se é verdade que a expansão dos investimentos públicos funcionou como um dos fatores dinamizadores do crescimento econômico durante 2005-2010, também é razoável admitir que a mudança para uma trajetória de queda da taxa de investimentos tenha favorecido a desaceleração econômica do período 2010-2014 e a crise de 2015, quando os investimentos públicos caíram a quase metade do patamar observado no ano anterior (Tabela 5). Principalmente quando se considera que, em conformidade com os resultados encontrados na análise empírica da seção 3, é justamente nos períodos recessivos que os multiplicadores dos investimentos alcançam valores mais elevados. Ao mesmo tempo em que as incertezas em relação ao contexto internacional adverso e ao regime fiscal tendem a desincentivar as inversões privadas e reduzir os possíveis impactos de subsídios e desonerações. Ou seja, a mudança na composição da política fiscal em favor dos subsídios e desonerações (e em detrimento dos investimentos públicos) pode ter contribuído para o malogro da estratégia de retomada do crescimento econômico ${ }^{24}$.

\section{Considerações finais}

Este artigo analisou a trajetória dos investimentos públicos na economia brasileira com ênfase no período recente caracterizado por um esboço de retomada (2005-2010) e inflexão para tendência de queda (2011-2015) que fez com que o avanço anterior já tenha sido quase todo revertido - e suas relações com ciclo econômico e regime fiscal. A análise da relação entre investimentos públicos e ciclo econômico se baseou nos resultados de um modelo econométrico não linear que permite estimar multiplicadores fiscais que variam conforme o estado da economia, seguindo a abordagem de Auerbach e Gorodnichenko (2012).

Os resultados corroboram as evidências encontradas na literatura internacional de que os multiplicadores fiscais diferem de acordo com os regimes recessivo/expansivo. Durante um período de quatro anos, a resposta do produto aos choques do investimento público em recessões fortes é sempre superior à unidade, persistente e alcança valores elevados (próximos ou superiores a 2 no período de maior impacto de 3 a 5 trimestres), sendo que o multiplicador de impacto máximo foi estimado em 2,2 (no décimo mês). Nas expansões fortes, em contrapartida, a resposta do produto é pouco persistente (não significativa a partir do sétimo trimestre) e sempre ficou abaixo da unidade com uma estimativa do multiplicador de impacto máximo de 0,8 (no sétimo mês).

(24) Uma avaliação mais precisa deste ponto exigiria uma estimação dos multiplicadores fiscais dos subsídios e desonerações. Algo que foge ao escopo desse trabalho. 
Investimento público no Brasil e suas relações com ciclo econômico e regime fiscal

Cabe aqui advertir que os multiplicadores do modelo não linear são considerados extremos. Em geral, a economia encontra-se transitando entre regimes expansivos e recessivos. Por isto, suas diferenças são superestimadas devido à pressuposição de que os regimes não mudam e pelo fato de considerar uma configuração com expansões e recessões fortes. Ao longo do tempo, o mais razoável é admitir que os multiplicadores assumam valores intermediários aos extremos. Algo que é consistente com o resultado também obtido neste artigo de um multiplicador de impacto máximo de 1,3 no modelo linear, sendo que a resposta do produto ao choque do investimento nesse modelo também se mostrou persistente convergindo para 0,8 ao longo de quatro anos.

Por um lado, esses resultados dão subsídios ao uso do investimento público como instrumento de política anticíclica, no sentido de que pode ser um instrumento de estímulo ao crescimento durante períodos recessivos. Ao mesmo tempo em que sugere cautela porque não se mostra tão eficiente em períodos expansivos. Por outro lado, os mesmos resultados sugerem que a retração da taxa de investimentos públicos, em conjunturas de desaceleração econômica como em 2011-2014 ou na crise de 2015, quando os multiplicadores assumem seus valores mais elevados, tem fortes repercussões negativas que contribuem para a deterioração do cenário macroeconômico.

É importante ressaltar, entretanto, que esta análise não pretende dar um tom generalista, justamente pelo fato de que se estuda uma vertente da política fiscal (os gastos de investimento) e não ela como um todo. Em outras palavras, o que se mensurou nesse artigo é o impacto marginal da execução de investimentos públicos sobre variáveis macroeconômicas, o que não quer dizer que esse tenha sido o efeito líquido da política fiscal em termos amplos. Sem dúvida, uma importante linha de avanço desta pesquisa seria estimar multiplicadores fiscais para os demais componentes dos gastos (ou mesmo das receitas).

Feitas estas constatações, o estudo passou a explorar os fatores que estão por trás da inflexão na trajetória da taxa de investimentos a partir de 2011. A hipótese central do texto diz respeito aos constrangimentos orçamentários aos investimentos que foram flexibilizados no período 2005-2010 e retornaram de maneira mais aguda durante 2011-2014. De maneira mais precisa, procurou-se mostrar que, a partir de 2011, a redução do espaço fiscal para investimentos foi um resultado inevitável da combinação entre rigidez da política fiscal, revelada por um componente estrutural e inercial dos gastos sociais, que já vinham crescendo desde a década de 1990, com a estratégia do governo de promover a retomada do crescimento via ampliação de subsídios e desonerações para o setor privado.

Isso ocasionou uma mudança na composição da política fiscal, com a passagem de um período no qual o espaço fiscal criado pelas flexibilizações no regime de metas foi canalizado predominantemente para investimentos públicos (2005-2010), para um período de maior crescimento dos subsídios e das desonerações (2011-2014), que, em parte, explica o malogro da estratégia de se retomar o crescimento. Do mesmo modo, a recente inflexão da política fiscal, do expansionismo do decênio 2005-2014 para nova fase de ajustamento iniciada em 
Rodrigo Octávio Orair, Fernando de Faria Siqueira

2015, também impôs cortes desproporcionais aos investimentos públicos, o que, dadas as elevadas estimativas de multiplicadores fiscais nos períodos recessivos desse artigo, tende a agravar ainda mais a situação econômica do país.

Procurou-se ainda apontar a fragilidade do mecanismo introduzido no regime fiscal para remover entraves orçamentários aos investimentos, uma vez que a margem de dedução de projetos prioritários de investimentos foi se desviando do seu propósito inicial e deixando de ter relação com esses investimentos, até culminar no seu abandono em 2015-2016. A fragilidade desse instrumento, juntamente com a rigidez da política fiscal, acaba por tornar a situação dos investimentos muito vulnerável no atual regime fiscal e aponta para um cenário pouco favorável nos próximos anos.

Refletir sobre esses aspectos é crucial no momento em que o país rediscute seu regime fiscal e atravessa profunda crise. O governo vem ensaiando uma reforma fiscal por meio da chamada proposta de nominalismo que estabelece uma regra de crescimento real nulo para as despesas primárias. Porém, pouco se tem debatido sobre o papel dos investimentos públicos. $\mathrm{O}$ aspecto crucial aqui é que a avaliação de alternativas de estratégias fiscais deve considerar de maneira mais explícita a composição da política fiscal e as repercussões dos investimentos públicos, no curto e no médio prazo, sobre o crescimento econômico e sobre a própria sustentabilidade fiscal. O propósito deste artigo é fornecer insumos para essas avaliações, a partir de estimações empíricas e reflexões sobre os erros e acertos do passado.

\section{Referências bibliográficas}

AFONSO, J. R.; BIASOTO JÚNIOR, G. Investimento público no Brasil: diagnósticos e proposições. Revista do BNDES, v. 14, n. 27, p. 71-122, jun. 2007. Disponível em: http://goo.gl/6tTjS9.

AUERBACH, A. J.; GORODNICHENKO, Y. Fiscal multipliers in recession and expansion. National Bureau of Economic Research, Inc, 2011. (NBER Working Papers).

AUERBACH, A. J.; GORODNICHENKO, Y. Measuring the output responses to fiscal policy. American Economic Journal: Economic Policy, v. 4, n. 2, p. 1-27, 2012.

AFONSO, J. R.; GOBETTI, S. W. Impactos das reformas tributárias e dos gastos públicos sobre o crescimento e os investimentos: o caso do Brasil. Santiago de Chile: Cepal, 2015. (Série Macroeconomia do Desenvolvimento, n. 167).

AFONSO, J. R.; VILMA, C. P.; FAJARDO, B. Dilemas do investimento público brasileiro: como salvar o futuro? Ensaios IBRE, Rio de Janeiro, 2015.

ALMEIDA, M. O paradoxo do investimento público no Brasil. Brasília: Ipea, 2009. (Nota Técnica).

BAUM, A.; POPLAWSKI-RIBEIRO, M.; WEBER, A. Fiscal Multipliers and the State of the Economy. International Monetary Fund, 2012. (IMF Working Papers). 
Investimento público no Brasil e suas relações com ciclo econômico e regime fiscal

BLANCHARD, O.; PEROTTI, R. An empirical characterization of the dynamic effects of changes in government spending and taxes on output. The Quarterly Journal of Economics, v. 117, n. 4, p. 1329-1368, 2002.

BIELSCHOWSKY, R. Investimento e reformas no Brasil: indústria e infraestrutura nos anos 1990. Brasília: Cepal; Ipea, 2002.

BLANCHARD, O.; GIAVAZZI, F. Improving the SGP through a proper accounting of public investment. London: Centre for Economic Policy Research, 2004. (CEPR Discussion Paper, n. 4220).

CALDERÓN, C.; EASTERLY, W.; SERVÉN, L. Latin America's infrastructure in the era of macroeconomic crises. In: EASTERLY, W.; SERVÉN, L. (Ed.). The limits of stabilization: infrastructure, public deficits, and growth in Latin America. Stanford: Stanford University Press, 2003. p. 21-94.

CÂNDIDO JÚNIOR, J. O. Efeitos do investimento público sobre o produto e a produtividade: uma análise empírica. Brasília: Ipea, 2006. (Texto para Discussão, n. 1204).

CASTELO-BRANCO, M. A.; LIMA, E. C. R.; PAULA, L. F. Mudanças de regime e multiplicadores fiscais no Brasil entre 1999-2012: uma avaliação empírica. In: ENCONTRO NACIONAL DE ECONOMIA, 43. Anais... Florianópolis: Anpec, 2015.

CERQUEIRA, B. S. Política fiscal, demanda agregada, crescimento e crise: o investimento federal e o investimento da Petrobras no período 2003-2015. Rio de Janeiro: IE/UFRJ, 2016. (Texto para Discussão, n. 27).

CORSETTI, G.; MEIER, A.; MLLER, G. J. What determines government spending multipliers? Economic Policy, v. 27, n. 72, p. 521-565, 2012.

COS, P. H. de; MORAL-BENITO, E. Fiscal multipliers in turbulent times: the case of Spain. Banco de España, 2013. (Working Papers).

FERREIRA, P. Investimento em infraestrutura no Brasil: fatos estilizados e relações de longo prazo. Pesquisa e Planejamento Econômico, v. 26, n. 2, 1996.

GOBETTI, S. W. Regras fiscais no Brasil e na Europa: um estudo comparativo e propositivo. Brasília: Ipea, 2014. (Texto para Discussão, n. 2018).

GOBETTI, S. W.; ORAIR, R. O. Flexibilização fiscal: novas evidências e desafios. Revista de Economia Contemporânea, v. 19, n. 3, p. 417-447, dez. 2015.

ILZETZKI, E.; MENDOZA, E. G.; VGH, C. A. How big (small?) are fiscal multipliers? Journal of Monetary Economics, v. 60, n. 2, p. 239-254, 2013.

KIRCHNER, M.; CIMADOMO, J.; HAUPTMEIER, S. Transmission of government spending shocks in the euro area: time variation and driving forces. European Central Bank, 2010. (Working Paper Series). 
Rodrigo Octávio Orair, Fernando de Faria Siqueira

MINTZ, J.; SMART, M. Incentives for public investment under fiscal rules. New York: Banco Mundial, 2006. (Policy Research Working Paper, n. 3860).

MORA, M. Evolução recente da dívida estadual. Brasília: Ipea, 2016. (Texto para Discussão, n. 2016).

ORAIR, R. O. A dinâmica recente dos gastos públicos brasileiros (III): a retomada do investimento público no Brasil e os desafios do padrão de financiamento. In: SANTOS, C. H.; GOUVÊA, R. (Org.). Finanças públicas e macroeconomia no Brasil: um registro da reflexão do Ipea (2008-2014). Brasília: Ipea, 2014. v. 2. p. 89-110.

ORAIR, R. O. Desonerações em alta com rigidez da carga tributária: o que explica o paradoxo do decênio 2005-2014? Brasília: Ipea, 2015. (Texto para Discussão, n. 2117).

ORAIR, R. O. Investimento público no Brasil: trajetória e relações com o regime fiscal. Brasília: Ipea, 2016. (Texto para Discussão, n. 2215).

ORAIR, R. O.; GOBETTI, S. Retomada do investimento público federal no Brasil e a política fiscal: em busca de um novo paradigma. In: CARDOSO JÚNIOR, J. C. (Org.). Brasil em desenvolvimento 2010: Estado, planejamento e políticas públicas. Brasília: Ipea, 2010. v. 1. p. 113-139.

ORAIR, R. O.; GOBETTI, S. W.; ALENCAR, A. A.; MARCELO, J. Fiscal condition of the public sector in Brazil: an analysis with an emphasis on the states in the Northand Northeast regions of the country and on financing for rural development. Brasília: IPC-IG, Apr. 2016. (Working Paper, n. 140).

ORAIR, R. O.; GOBETTI, S. W.; LEAL, E. M.; SILVA, W. J. Carga tributária brasileira: estimação e análise dos determinantes da evolução recente - 2002/2012. Brasília-DF: Ipea, 2013. (Texto para discussão, n. 1875).

ORAIR, R. O.; GOUVÊA, R. R.; LEAL, E. Ciclos políticos eleitorais e investimentos das administrações públicas no Brasil. Brasília: Ipea, 2014. (Texto para Discussão, n. 1999).

PÊGO FILHO, B.; CAMPOS NETO, C. A. da S. (Org.). Infraestrutura econômica no Brasil: diagnósticos e perspectivas para 2025. Brasília: Ipea, 2010. v. 1.

PÊGO FILHO, B.; CÂNDIDO JÚNIOR, J. O.; PEREIRA, F. Investimento e financiamento da infraestrutura no Brasil: 1990/2002. Brasília: Ipea, 1999. (Texto para Discussão, n. 680).

PIRES, M. Controvérsias recentes sobre multiplicadores fiscais. In: ENCONTRO INTERNACIONAL DA ASSOCIAÇÃO KEYNESIANA BRASILEIRA, 7. Anais... São Paulo: AKB, 2011.

PIRES, M. Política físcal e ciclos econômicos no Brasil. Economia Aplicada, v. 18, n. 1, p. 69-90, jan./mar. 2014. 
Investimento público no Brasil e suas relações com ciclo econômico e regime fiscal

SCHAECHTER, A.; KINDA, T.; BUDINA, N. T.; WEBER, A. Fiscal rules in response to the crisis-toward the next-generation rules: a new dataset. New York: Fundo Monetário Internacional, 2012. (Working Paper, n. 12/187).

SCHETTINI, B. et al. Balanço estrutural e impulso fiscal: uma aplicação para o Brasil (19972010). Brasília: Ipea, 2011. (Texto para Discussão, n. 1650).

SERVÉN, L. Fiscal rules, public investment, and growth. New York: Banco Mundial, 2007. (Policy Research Working Paper, n. 4382).

WARNER, A. M. Public investment as an engine of growth. Washington: IMF, Aug. 2014. (IMF Working Paper, n. 148).

WOODFORD, M. Simple analytics of the government expenditure multiplier. American Economic Journal: Macroeconomics, v. 3, n. 1, p. 1-35, 2011. 